\title{
UN MÉTODO INÉDITO PARA APRENDER ÁRABE ARGELINO ESCRITO EN MOSTAGANEM EN LOS AÑOS 1970: PRESENTACIÓN, CONTEXTO Y ESTUDIO LINGÜÍSTICO
}

\section{AN UNPUBLISHED METHOD FOR LEARNING ALGERIAN ARABIC WRITTEN IN MOSTAGANEM IN THE 1970S: PRESENTATION, CONTEXT AND LINGUISTIC STUDY.}

\author{
منهجية جديدة لتعلّم اللهجة العربية الجزائرية المتداولة بمدينة مستغانم خلال سنوات السبعينات:$$
\text { تقديم والسياق ودراسة لسانية }
$$ \\ Francisco Moscoso García* \\ Universidad Autónoma de Madrid
}

BIBLID [1133-8571] 28 (2021) 104.1-24

Recibido: 20/05/21 Aceptado: 20/07/21

Resumen: se da a conocer en este artículo un método inédito que se emplea en la enseñanza del árabe argelino en la diócesis de Orán. Fue elaborado en Mostaganem entre 1970 y 1978 por tres sacerdotes. Se hace una presentación de la génesis de la obra, situándolo en un contexto en el que fue elaborado un segundo método, kama:l, y recopilaciones de textos en árabe argelino moderno. Y, por último, exponemos los rasgos lingüísticos más relevantes.

Palabras clave: Argelia, región oranesa, árabe de Mostaganem, árabe argelino, diócesis de Orán.

Abstract: This article presents an unpublished method used in the teaching of Algerian Arabic in the diocese of Oran. It was developed in Mostaganem between 1970 and 1978 by three priests. We present the genesis of the work, placing it in the context in which a second method, kama:l, and some compilations of texts in modern Algerian Arabic were developed. Finally, the most relevant linguistic features are presented.

Keywords: Algeria, Oranese region, Mostaganem Arabic, Algerian Arabic, Diocese of Oran.

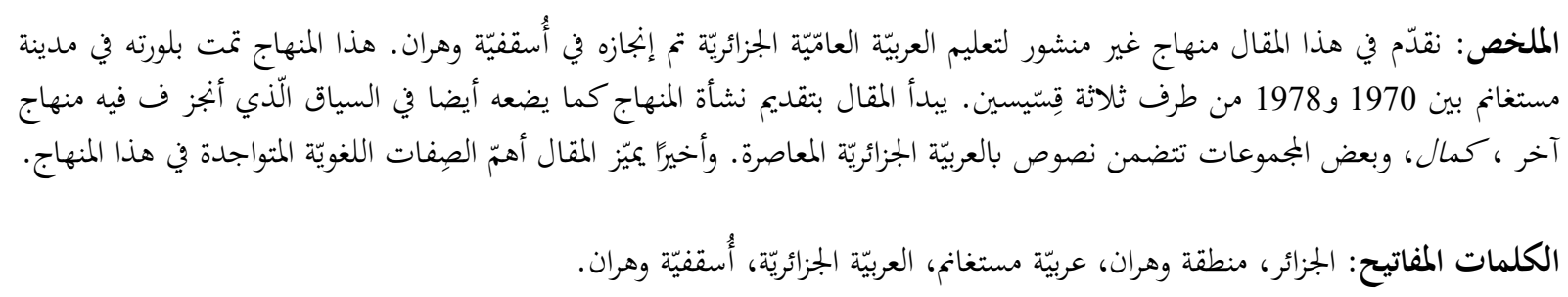

* Email: francisco.moscoso@uam.es. ORCID: https://orcid.org/0000-0002-2880-4540. 


\section{Introducción}

Argelia estuvo bajo la colonización francesa desde 1830 hasta 1962. La independencia tuvo lugar después de una guerra en la que el pueblo argelino supo liberarse de tantos años de dominio. El Frente de Liberación Nacional (FLN) puso en práctica una serie de medidas para arabizar un país en donde la lengua francesa se había casi impuesto en el terreno educativo. La Administración estaba también bastante afrancesada y había una enorme carencia de profesores. La llegada al poder en 1965 de Boumediene, después de Ben Bella, este primer presidente, supuso un aliento importante para la arabización (Grandguillaume 1983: 95-134). Argelia -así lo expresa Tapiéro (1971: V)-éprouvait le désir ardent d'une " arabisation» profonde et rapide de sa langue écrite et parlée. Es en este contexto en el que hay que situar los textos en árabe argelino moderno que Mahmoud Fekhar y Gabriel Deville publicaron entre 1966 y 1977 (Moscoso 2017), los textos radiofónicos de Ali Feddi y Gabriel Deville, publicados entre 1973 y 1975 o el Manuel de Tapiéro (1971) en la misma variedad.

Estos esfuerzos para arabizar al país, ya sea en la variedad árabe literal o la variedad intermedia entre aquella y la lengua árabe materna, también se dirigieron indirectamente a la población extranjera que trabajaba en él, cooperantes o religiosos y religiosas principalmente, pero esta prefirió, sobre todo, instruirse en la variedad árabe materna o nativa. Es en este contexto en el que situamos el método inédito que presentamos, pero también kama:l (1983), enseñado a partir de 1970 en el Centro diocesano Les Glycines de Argel, o las colecciones de textos publicadas en 1957 por Tapiéro y en 1963 por Darmaun respectivamente.

Hemos calificado en nuestro título a la Méthode A.P.M. (arabe parlé à Mostaganem) como inédita. El diccionario de la Real Academia Española define este adjetivo como "escrito y no publicado", pero también como "desconocido, nuevo". El método fue escrito en 1970, pero no fue publicado, solo se empleaba para la enseñanza del árabe argelino en Mostaganem, Arzew y Orán entre los cooperantes y religiosos que trabajaban en la región oranesa. Excepto una interrupción en la década de 1990 a 2000, debido a la guerra, sigue siendo un manual de enseñanza hoy día en la diócesis de Orán. Por otro lado, es desconocido fuera de las fronteras de esta zona y, hoy día, fuera del ámbito de dicho territorio eclesiástico. Su distribución es gratuita para todos aquellos que deseen aprender árabe argelino. En el transcurso de una estancia Erasmus + , que llevamos a cabo en la Universidad Orán I Ahmed Benbella entre el 10 y 14 de marzo de 2019, la hermana blanca Danuta Kmieciak, que dirige una biblioteca en la ciudad, nos pasó a una memoria USB los textos y audios.

Nuestro objetivo en este trabajo será el de presentar este método, situándolo en el contexto de otros publicados en torno a 1970, y destacar el análisis lingüístico de los diálogos. Lo acompañaremos de un apéndice en el que incluiremos algunos de sus textos: la transcripción empleada, un diálogo, parte del glosario, ejercicios y contenidos gramaticales. Por último, nos gustaría agradecer en esta introducción a la hermana Danuta Kmieciak el habernos dado a conocer este material y al P. Philippe Moysan, quien, con el P. Michel Vidil, colaboró en la elaboración del método junto a su impulsor, el P. Jean Paul Champenois, el haber respondido a mi correo y haberme dado todos los detalles de su gestación. Ha sido, además, gracias al P. Moysan que el método sigue vivo, ya que él emprendió su reedición en 2002.

\section{La Méthode A.P.M. y la enseñanza del árabe argelino en torno a los años 1970}

En un artículo que publicamos en 2017, dimos a conocer los textos en árabe argelino moderno que escribieron Mahmoud Fekhar y el P. Gabriel Deville entre 1966 y 1972 en aras a contribuir a la arabización tras la independencia de Argelia en 1962. En este trabajo dimos cuenta de un documento en PDF que nos fue enviado por Michel Gillaume el 4 de marzo de 2014, director en aquel momento del Centro de Estudios Diocesanos Les Glycines ${ }^{(1)}$,

(1) https://www.glycines.org/ [consultado el 21 de mayo de 2021]. 
perteneciente a la diócesis de Argel. Este documento lleva por título "Documents \& méthode d'enseignement de l'arabe algérien", y fue escrito por la profesora Aziza Boucherit el 21 de julio de 2012. Contiene cuatro páginas y en él se reseña el material de Fakhar y el P. Deville y el método kama:l. Esta última obra estaba operativa en 1970, ya que con él estudiaron -tal como leeremos más abajo- el autor principal del método de árabe hablado en Mostaganem, el P. Champenois, y, que sepamos, el P. Moysan. Su impulsor fue el que fuera director del Centro Les Glycines entre 1966 y 1973 y arzobispo de Argel entre 1988 y 2008, Mons. Henri Tessier (1929-2020); en 1971, el método ya era enseñado al completo, siendo más tarde mejorado con los ejercicios realizados por el P. Pièrre Georgin, quien defendió una tesis doctoral en 1980 en la Universidad René Descartes de París con el título Esquisse phonologique et détermination nominale du parler árabe d'Alger. El método lleva por título kama:l. Méthode S.G.A.V. Arabe parlé algérien (Alger). Dialogues et lexique, Alger, Centre d'études diocésain, 1984, y sigue enseñándose hoy día en el Centro de Estudios Diocesanos Les Glycines. Es un método "estructural-global, audio-visual" (S.G.A.V.), basado en el árabe de Argel, técnica que reproduce también el que presentamos en este artículo; está estructurado en 45 lecciones, divididas en tres años de estudio.

En la misma línea que los textos de Fakhar y el P. Deville, conviene mencionar la obra Manuel d'arabe moderne, escrita por Tapiéro en 1971, dividida en treinta lecciones y un glosario árabe-francés, francés-árabe al final con todas las voces que aparecen. Las dos primeras unidades están dedicadas a la fonética del árabe argelino moderno y las restantes comienzan por un texto, en transcripción y grafía árabe, seguido del vocabulario, un ejercicio y un tema; algunas lecciones también ofrecen contenidos gramaticales. El sistema seguido es el mismo que kama:l o la Méthode A.P.M., es decir, estructural. El autor explica en el prefacio que les textes ont été tous, plus ou moins, retouché par apport au Manuel d'arabe algérien (Tapiéro 1957), certains même profondément dans l'esprit et dans la forme. Tapiéro (1971: V) se pregunta cómo arabizar una lengua, el árabe argelino, siendo ya árabe; su propuesta es la de reemplazar los préstamos de lenguas extranjeras y "las voces árabes inapropiadas" por nuevas palabras procedentes del árabe literal moderno, así como estructuras gramaticales y partículas adverbios, preposiciones, conjunciones- procedentes también de esta variedad, conservando aquellos términos relacionados con la vida cotidiana y la tradición. Por último, es interesante destacar que en su manual de árabe moderno colaboraron Ali Feddi y el P. Gabriel Deville, este último responsable de la enseñanza del árabe en Les Glycines. Feddi fue quien con su voz leyó los textos del manual y fueron grabados ${ }^{(2)}$. También le debemos a él y al P. Gabriel Deville una colección de textos en árabe argelino moderno, al estilo de los que escribió con Fakhar, y que fueron publicados por el centro de Les Glycines ${ }^{(3)}$. Son ocho cuadernos que fueron publicados entre 1973 y 1975 y llevan por título general Arabe algérien moderne (emissions radiophoniques) $)^{(4)}$.

(2) Pueden oírse en línea en https://archive.org/details/Track30/-+Track10+().mp3, consultado el 04 de mayo de 2021.

(3) Pueden consultarse las referencias en el catálogo de la biblioteca de Les Glycines: https://www.glycines.org/la-biblioth\%C3\%A8que/, consultado el 04 de mayo de 2021.

(4) Los títulos de los cuadernos son estos:

Cahier $\mathrm{N}^{\circ} 1-1973:$ «Le foyer heureux » :-Parents et enfants -Le rachitisme -Bains salés et Bains de soleil Page culinaire.

Cahier N²-1973 : «Bulletin d'informations », «La terre et le fellah» : Nouvelles techniques -Production des légumes primeurs -Courrier des auditeurs.

Cahier $N^{\circ}$ 3-1973 : «Le médecin de famille » : Valeur thérapeutique de l'eau de mer - Utilité des bains de mer -Le mal de mer. 
Antes de presentar el "método inédito", conviene presentar la obra Recueil de Textes algériens, escrita por Darmaun en 1963, un año después de la independencia. Este libro también podemos incluirlo en el grupo de obras anteriormente reseñadas. En el prefacio a la obra, escrito por Régis Blachère, se advierte de que la colección de textos es continuación del Manuel d'arabe algérien escrito por Tapiéro (1957). La obra se compone de 76 textos solo en transcripción y van acompañados de contenidos gramaticales, un ejercicio de conversación y un tema. Al final de la obra hay un glosario árabe-francés, francés-árabe con todas las voces, que -según comenta en el prólogo Blachère-placé à la fin du volume est judicieusement conçu comme un complément à celui du volumen de M. Tapiéro.

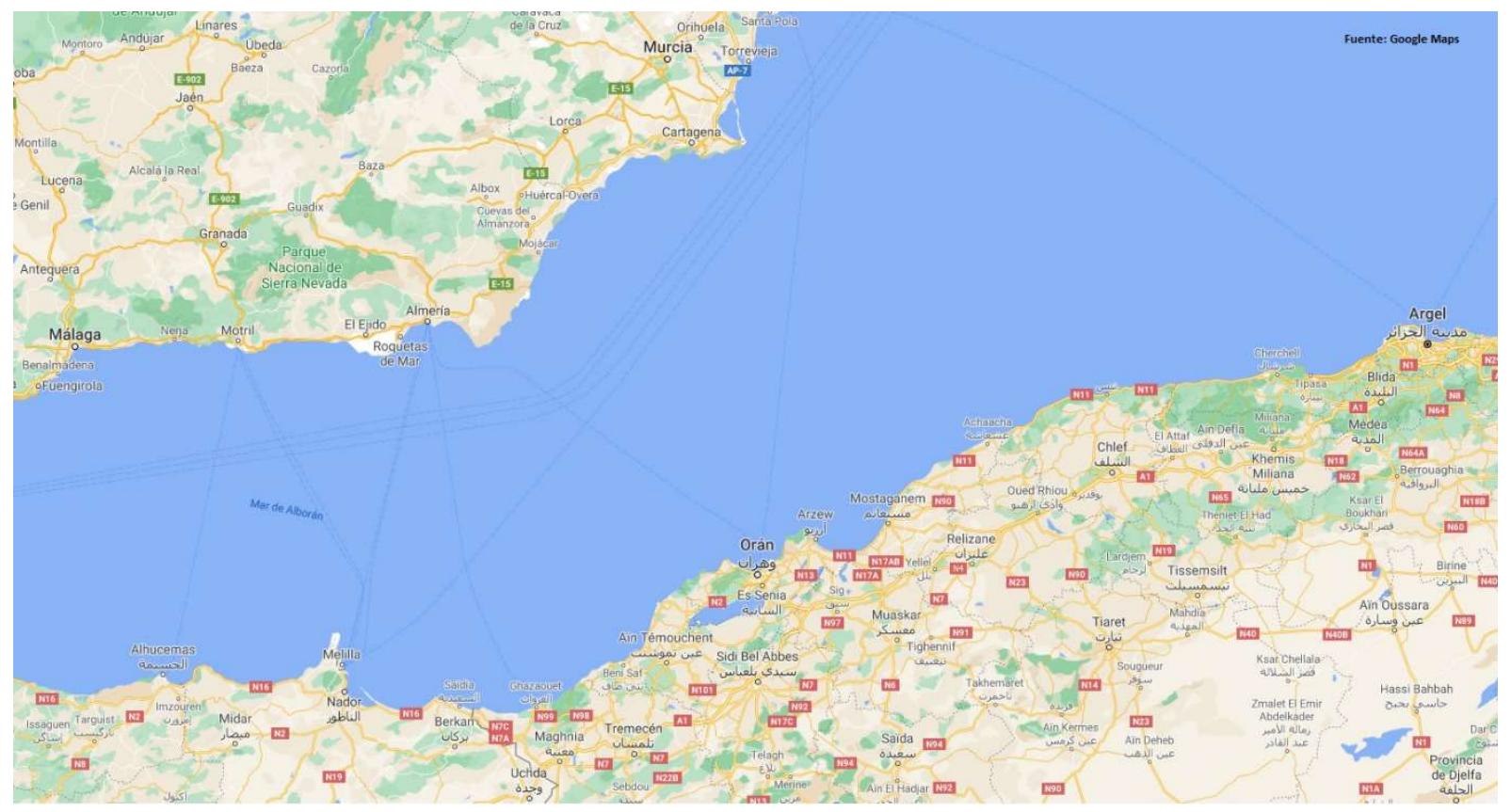

El método objeto de nuestro estudio lleva por nombre Méthode A.P.M. (árabe parlé à Mostaganem), comenzó a hacerse en 1970, tal como expondremos a continuación, y se acabó el 31 de mayo de 1978, fecha que figura al final del texto de la lección 90 y que va seguida del nombre "Michel", entendemos que es el P. Michel Vidil, y el de Aouicha, la profesora nativa a la que se menciona en el texto. En la presentación se dice que es un manual de árabe argelino escrito en Mostaganem por el P. Jean Paul Champenois, con la ayuda del P. Michel Vidil, este último fue el que dio difusión al método. La diócesis de Orán y, en su nombre, el P. Philippe Moysan, hizo posible una reedición entre 2002 y 2006 con diaporamas hasta la lección 16, hechos por Louis Fontugne, y audios en formatos WMA y MP3, haciendo constar lo siguiente sobre los derechos de autor:

Cahier $\mathrm{N}^{\circ}$ 4-1974 : «La formation professionnelle », « Bulletin météorologique », « Journal télévisé », « Revue de presse ».

Cahier $N^{\circ}$ 5-1974 : « L'orientation scolaire et professionnelle » : Semaine de l'information - La spécialisation

Cahier $N^{\circ}$ 6-1974 : «Le foyer heureux » : Mesures prophylactiques ...stérilisation de l'eau...lavage des légumes et des fruits...hygiène des nourrissons.

Cahier N 7-1975 : «Propos religieux », 1er Novembre 1974 : 20ème Anniversaire de la Révolution Algérienne.

Cahier N ${ }^{\circ}$ 8-1975 : « Discours du Chef de l'Etat » (1ère moitié) au Premier Congrès Constitutif de l'UNPA Union nationale des Paysans. 
L'engagement financier du diocèse d'Oran n'ayant pas non plus vocation à être récupéré par le produit de la vente, les CD-Rom sont cédés au prix coutant et chacun est libre de recopier le CD pour le diffuser dans son entourage, sans autre profit que celui de l'apprentissage de la langue. Car il est évident que ces copies de la méthode ne devront en aucun cas être revendues à des fins commerciales.

El P. Moysan, con quien nos pusimos en contacto recientemente por correo electrónico para que nos ilustrara sobre cómo se fue gestando el método, nos respondió amablemente el 02 de mayo de 2021. En su carta, nos remitía a la introducción del método, de cuyos datos sobre autoría y estructura damos cuenta en esta presentación junto a aquellos aportados por él. Nos contó que el P. Vidil fue nombrado a la parroquia de Mostaganem en 1970 y él, el mismo año, a la parroquia de Arzew, localidades de la región oranesa situadas en la costa, a unos $50 \mathrm{~km}$ de distancia una de la otra. Mientras tanto, el P. Jean Paul Champenois se iniciaba en el árabe argelino en Argel con el método kama:l. En Arzew, el P. Moysan, que ya se había iniciado en el árabe argelino después de ser nombrado a la diócesis de Orán en 1965, enseñaba esta lengua a los cooperantes franceses con ayuda de monitores nativos. El P. Champenois vuelve de Argel después de un año y comienza a trabajar como profesor en Mostaganem. Se siente incapaz de comunicarse en árabe argelino, lo cual achaca al método kama:l, que tenía sus virtudes, pero también sus fallos. Tanto el P. Champenois como el P. Moysan, quien también hizo un año de aprendizaje con el método kama:l, estaban de acuerdo en que este se basaba sobre todo en la adquisición de vocabulario y las lecciones eran muy largas, había que aprender de memoria las conjugaciones antes de abordar los textos, no había lugar para asimilar las estructuras de las frases y carecía de pedagogía. Sobre esto último, destacaban que se comenzaba inmediatamente por los verbos "tener" y "ser", sin tiempo suficiente para asimilarlos, luego se pasaba al imperfectivo y a continuación al perfectivo, sin que aquel se hubiera asimilado bien.

El P. Champenois decidió que debía de aprender árabe argelino y que tenía que hacer un nuevo método. Su colega, el P. Vidil tenía buenos conocimientos de árabe clásico, ya que había estudiado en el PISAI ${ }^{(5)}$, pero no poseía tantos de árabe argelino. El P. Champenois, el P. Vidil y el P. Moysan eran buenos amigos, lo cual les motivó para hacer frente a este reto, y, además, contaban con la ayuda de amigos nativos en Mostaganem, Arzew y Orán, aunque el artífice principal del método fue el $\mathrm{P}$. Champenois, quien, con ayuda también de nativos, confeccionó los 90 diálogos, que fueron revisados por el P. Vidil. Aquel escribió además las fichas gramaticales de las primeras 40 lecciones, todo ello en transcripción, sin emplear para nada la grafía árabe. El P. Vidil se encargó de la policopia y de la escritura del texto árabe para los diálogos, la gramática quedó enteramente en transcripción. Al comienzo, el P. Champenois hacía llegar los diálogos al P. Moysan y este los ponía en práctica en sus cursos en Arzew, haciéndole llegar algunas pequeñas correcciones, a excepción de las primeras lecciones, que mandó rehacer para que fueran introduciendo poco a poco las letras árabes, difíciles de pronunciar para los discentes no arabófonos. Y, además, fue redactando ejercicios a medida con los que se iban asimilando las lecciones. Los cursos de la Méthode A.P.M. fueron impartidos en Arzew, Mostaganem, Orán, Tiaret y Mascara, sobre todo, a cooperantes, la mayoría profesores franceses, y también a religiosos y religiosas. En los años 1980, la arabización hizo que los profesores de primaria y secundaria regresaran a Francia, solo se quedaron algunos universitarios. Durante el "decenio negro" que vivió Argelia, los extranjeros se fueron casi todos y los cursos se interrumpieron. El P. Champenois vuelve definitivamente a Francia en

(5) Instituto Pontificio de Estudios Árabes e Islámicos: https://www.pisai.it/ [consultado el 21 de mayo de 2021]. 
1990 y el P. Vidil lo hará en 1996, volviendo a Orán en 2001, pero regresando a Marsella un año más tarde para tratar un cáncer, y muriendo varios meses más tarde ${ }^{(6)}$.

Terminada la "década negra", los cursos fueron retomados. El P. Champenois había dejado al P. Moysan todo el material antes de su partida, pero los esténciles originarios no podían ser utilizados, tampoco había policopiadoras que funcionaran. Y es entonces, a partir de 2002, cuando decide pasar todo el método a soporte informático, aprovechando las nuevas facilidades para escribir que le ofrecía el Word y el PowerPoint, entre otras, la de emplear la grafía árabe; a ello, sumó unas nuevas grabaciones con una mejor calidad. Por aquel entonces ya no trabajaba en la zona industrial de Arzew y pudo dedicarse a esta tarea por entero. El trabajo consistió en pasar a PDF los diálogos 1-60 y escanear los 61-90 del P. Champenois, estos últimos escritos a mano; las fichas de gramática de las lecciones 1-40 del P. Champenois, en transcripción y grafía árabe; las fichas de gramática de las lecciones 1-60, en transcripción solo, del P. Moysan; las fichas de los ejercicios, en escritura árabe manuscrita, de las lecciones 1-55, del P. Moysan; las fichas de aprendizaje de la escritura árabe del P. Moysan; y el léxico de las lecciones 1-30, solo en transcripción, del P. Moysan. En cuanto al audio, este padre grabó en MP3 los diálogos y ejercicios de las lecciones 1-60. Los diaporamas de las lecciones 1-16 también fueron hechos por él, no pudiendo continuar, ya que el dibujante perdió la vista; intentó buscar a otro, pero las pruebas que hizo de la lección 16 no le resultaron satisfactorias. Finalmente, el P. Moysan nos decía en su correo que los 30 primeros diálogos sufrieron algunos pequeños cambios con una intencionalidad pedagógica ayudados por amigos de Mostaganem, Arzew y Orán.

En total son 90 lecciones, divididas en bloques de treinta, cada uno se corresponde con un año de estudio. Cada lección contiene un diálogo, escrito en grafía árabe y transcripción, con su traducción al francés. Los diálogos 1-60 están escritos en ordenador, mientras que los 61-90 lo están a mano, y han sido escaneados. La portada de cada uno de los bloques hace constar que fueron escritos en octubre de 2006. Van acompañados de otro bloque de PDF con ejercicios, que solo llegan hasta la lección 60; de estos, a partir de la lección 31 están escritos a mano; están basados en pronunciación, preguntas sobre el diálogo, temas con expresiones habituales y ejercicios del tipo de los drills, todos acompañados de su solución. Le siguen otros PDF con cuestiones gramaticales, con fecha de 2003, hasta la lección 60, solo en transcripción y escrito al ordenador. Y un léxico árabe-francés y viceversa, en transcripción y escrito al ordenador, que abarca hasta la lección 30. A este material se añaden unos ejercicios de escritura en grafía árabe con una portada en la que se hace constar que fueron realizados en 2006.

Los audios de los diálogos solo llegan hasta la lección 60, a los que se suma una historia de Yuha. Los ejercicios también van acompañados de su audio correspondiente, pero solo hasta la lección 55. Los formatos de todos los audios están tanto en WMA como MP3. Y, por último, se incluye un repertorio de diaporamas solo de las 16 primeras lecciones; en cada uno de ellos, visualizado a través de PowerPoint, puede oírse el diálogo correspondiente a partir de dibujos que representan lo que se dice en este. En conclusión, el método recoge 90 diálogos, pero los ejercicios a partir de la lección 61 faltan, la gramática solo llega hasta la lección 60, los audios solo están hasta la lección 55, los diaporamas hasta la 16 y el glosario hasta la 30.

Los "principios del método" son cuatro: "la adquisición de estructuras de frases", antes del vocabulario, ya que el discente, que vive en Argelia, tendrá la oportunidad de ir haciéndose con un acopio de voces en su día a día; la "memorización" de las lecciones, que son cortas; la "progresión rigurosa", comenzando por la gramática, y sobre esta se pone el acento primero en la oración nominal y luego en los verbos, la partícula concomitante $r \bar{a}$ - y el futuro, aprendiendo primero el imperfectivo y, más tarde, el perfectivo; y "la lección de revisión" cada cinco lecciones. Cada lección es estudiada durante una semana, no abordándose el estudio de la

(6) Cf. Necrológica que nos fue enviada por el archivero general de los padres blancos en Roma el 27 de abril de 2021: "Pérez Michel Vidil, 1930-2002", pp. 188-191. 
gramática hasta llegar a la sexta semana. La escritura empleada es tanto la árabe como una transcripción de esta. Los textos en árabes están mínimamente vocalizados. El alumno va aprendiendo la grafía árabe poco a poco durante las primeras nueve lecciones.

El método empleado puede enmarcarse en los conocidos como "audiolingual", empleado a partir de los años 1940, y cuya base fue la lingüística estructuralista y la sicología conductista. En este método, los ejercicios conocidos como drill están basados en la repetición hasta la memorización. El principal objetivo es la adquisición de competencias orales. El error de este método fue el incidir en el aprendizaje de estructuras, dejando en un segundo plano su uso en situaciones reales, aunque en el caso del método de Mostaganem, estas están representadas, al menos en parte, en los diálogos, lo cual supone un avance. Y, además, el Méthode A.P.M. se enseña in situ, en la región oranesa, lo cual supone un aliciente para el alumno, ya que puede poner en práctica lo aprendido e ir ampliando su vocabulario.

\section{Análisis lingüístico}

Argelia es un país que tiene cuatro veces la extensión de España. Cantineau dividió sus distintas variedades árabes en cuatro grandes regiones: Constantina (Cantineau 1938-1939), Argel (Cantineau 1937), Orán (Cantineau 1940) y Sáhara (Cantineau 1941). Aunque podemos encontrar variedades sedentarias, la inmensa mayoría son hoy en día beduinas o han sido fuertemente beduinizadas, es el caso de Argel (Boucherit 2002). No nos detendremos aquí en hacer una exposición más amplia sobre el haz dialectal argelino, ya que ha sido hecha en Moscoso 2020a y Moscoso 2020b, pero sí conviene que hablemos sobre la región oranesa.

Presentamos en esta sección los rasgos lingüísticos más destacados del método. Hay que tener en cuenta que, si bien los diálogos fueron elaborados en Mostaganem, los 30 primeros sufrieron algunos retoques con fines pedagógicos, a decir del P. Moysan en su correo electrónico, y que, para ello, fueron ayudados por amigos de Mostaganem, Arzew y Orán. Este dato es importante tenerlo en cuenta, ya que puede que haya alguna característica que no se dé en el árabe de Mostaganem, aunque no creemos que sea relevante. Las tres ciudades están próximas, Mostaganem dista unos 60 kilómetros de Arzew y 80 de Orán. Nosotros hemos considerado los rasgos abajo expuestos como pertenecientes al árabe de Mostaganem.

Las tres ciudades antes mencionadas están dentro de la región dialectal descrita por Cantineau (1940), quien habla de cuatro variedades árabes en esta zona. Si bien es cierto que han pasado más de treinta años desde esta descripción hasta que comenzó a escribirse el método, y que el movimiento de población desde el desierto y la campiña hacia las ciudades ha sido considerable, podemos tener en cuenta esta clasificación en aras a un posible trabajo de campo que nos permita apreciar la evolución de estas variedades a lo largo de estos años. Estas son las siguientes: las sedentarias de los musulmanes de Mostaganem, los judíos de Aflou y los musulmanes de Tremecén; las sedentarias de montaña de los musulmanes de Msirda y Trara al norte de Tremecén y los judíos de Tremecén; las nómadas (dialectos tipo B) en el Tell que rodea Mostaganem; y el de los nómadas de Ulād Brahīm de Saïda ${ }^{(7)}$ y los alrededores de Tremecén, Orán y Sidi-Bel-Abbès (tipo D). Sobre lo dicho por este dialectólogo con relación a Mostaganem, cabe destacar lo siguiente: á Mostaganem, le parler de sédentaires est tout pénétré d'apports nómades: il paraît devoir se perdre bientôt (Cantineau 1940: 223). Por lo dicho anteriormente, la ciudad debía de estar sufriendo un importante proceso de beduinización, lo cual queda de manifiesto en los rasgos que a continuación expondremos, los cuales compararemos con los pocos detallados por Cantineau (1940: 222-223) para la variedad sedentaria de Mostaganem. A esta clasificación habría que añadir subgrupos como el del tipo Bd (Muaskar / Máscara), Ba (Tiaret) y los que están en transición hacia el Sur, tipos Ad

(7) Cf. Marçais 1908 . 
(Géryville / El Bayadh) y Da (Méchéria y Aïn Séfra). Las variedades del tipo A son nómadas del Sáhara (Moscoso 2020b).

\subsection{Vocalismo y consonantismo ${ }^{(8)}$}

2.1.1. Poco podemos decir sobre el vocalismo breve, ya que los datos escritos y auditivos no nos permiten establecer conclusiones.

2.1.1.1. En algunos verbos, hay alternancia vocálica. Ejemplos: tadxəl "tú entrarás" (m.) -

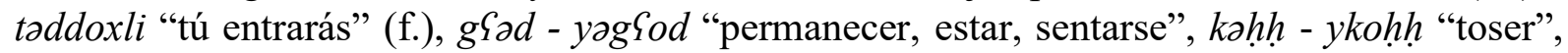
d̊nn - yḍonn "pensar, creer", șaqșa - yṣoqși "preguntar".

2.1.1.2. En cuanto a los diptongos, hay una tendencia a la monoptongación, pero el diptongo se mantiene en algunas voces. La monoptongación es un rasgo de los nómadas del grupo B (Cantineau 1940: 226). Ejemplos: $d_{\bar{i}} \bar{q}$ "estrechez", bìt "habitación", sīf "verano", zìtūn "aceitunas", zìt "aceite", hūma "barrio", mawצìn "vajilla (acción de lavarla)", d’yfa "invitada", bəyḍ "huevos", ḩwš "patio".

2.1.1.3. La labialización es un fenómeno aislado que aparece solo en $m m^{w} ə k$, junto a $m m \bar{u} k$, "tu madre".

2.1.2. En Mostaganem se pone de manifiesto lo dicho por Grand'Henry (1976: 15), a saber, que la distinción entre dialectos sedentarios y beduinos atendiendo a la realización de $\boldsymbol{q},[\mathbf{q}] \mathbf{y} \mathbf{~} \mathbf{g}]$ respectivamente, no está tan clara, pudiendo hablar de zonas de transición. Cantineau (1940: 222) decía que la variedad sedentaria de Mostaganem se caracterizaba por la pronunciación [q], pero que en muchas voces estaba "cediendo el lugar a [g]". Si bien nuestros ejemplos con [g] son más numerosos, hay bastantes con [q]. Ejemplos: ysūg "conduce", ygūlu "dicen", grīb "cerca", sūg "mercado", təggoЯdi "tú permanecerás, estarás" (f.), taggalఢu "arrancáis", trīg "camino", füg "sobre", mgaț̣īn "hecho pedazos", grīb "cercano", gallīl "miserable, desgraciado", pl. glālīl, bagra "una vaca", guffa "cesta", rgīg "delgado", nqərṛi "enseño", mqallaq "agobiado", gāl-ygūl "decir", rgadti "tú has dormido" (f.), yəbqa "queda, permanece", $q \bar{a} r \partial \zeta$ - yqārəS "esperar", kunt nəqra "estaba leyendo", nnəqqi "yo limpio".

2.1.2.1. Hemos encontrado un caso aislado de paso de $\boldsymbol{q} / \boldsymbol{g}>\dot{\boldsymbol{g}}$ en la voz $\dot{g} u r y \bar{a} n$ (< quryān / guryān) "bebé". Este rasgo no es sistemático en los dialectos del grupo B, sino residual, como ġalb (qalb / galb) "corazón” (Cantineau 1940: 225). También lo es en el grupo A (Moscoso 2020b: 148) : lg $a(<\operatorname{lqa} / \lg a)$ "él fue al encuentro". En los tres casos, parece que se debe a la presencia de una vibrante o una lateral.

2.1.2.2. La realización de $\breve{g}$ es [ $\breve{g}]$, que Marçais (1977: 9) sitúa en los dialectos urbanos y rurales de Tremecén, Ténès, Cherchell, Médéa, Miliana, Blida, Alger, Dellys, Mila y Constantina y entre los beduinos de las mesetas y el Altiplano del centro y el oeste de Argelia, por el contrario, [ž] es la

(8) Los fonemas consonánticos del árabe de Mostaganem son: $b$ (oclusiva bilabial sonora), $w$ (semiconsonante bilabial), $m$ (nasal bilabial), $f$ (fricativa labiodental sorda), $t$ (oclusiva dental sorda), $t$ (oclusiva dental sorda velarizada), $d$ (oclusiva dental sonora), $d$ (oclusiva dental sonora velarizada), $s$ (sibilante alveolar sorda), $s$ (sibilante alveolar sorda velarizada), $z$ (sibilante alveolar sonora), $l$ (lateral), $l$ (lateral velarizada), $r$ (vibrante), $r$ (vibrante velarizada), $n$ (nasal dental), $\check{s}$ (chicheante prepalatal sorda), $\breve{g}$ (africada prepalatal sonora), $y$ (semiconsonante prepalatal), $k$ (oclusiva palato-velar sorda), $g$ (oclusiva palato-velar sonora), $q$ (oclusiva uvulo-velar sorda), $x$ (fricativa posvelar sorda), $\dot{g}$ (fricativa posvelar sonora), $h$ (fricativa faringal sorda), $\subseteq$ (fricativa faringal sonora), $h$ (fricativa glotal sorda). 
realización de las variedades beduinas del sur de Orán, Argel y Constantina, como hemos puesto de manifiesto en Moscoso (2020b: 147) y también es corroborado por Grand'Henry (1976: 13). También es $\breve{g}$ para el grupo B de nómadas limítrofe con Mostaganem (Cantineau 1940: 225). Ejemplos: hāăga

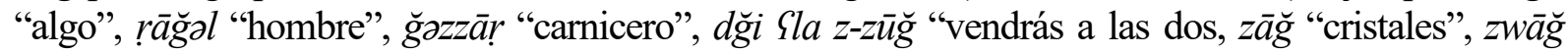

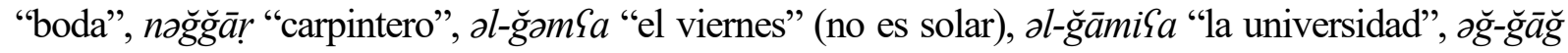

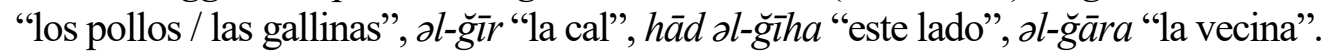

2.1.2.2.1. La $\breve{g}$ no pasa a $g$ ante la $z$, al igual que el grupo beduino B (Cantineau 1940: 225). Ejemplo: $९ \breve{g} \bar{u} z a$ "abuela, anciana", $\breve{g} ə z z \bar{a} r$ "carnicero".

2.1.2.3. En cuanto al consonantismo, destacamos la ausencia de interdentales, realizándose estas como oclusivas; esto ya había sido señalado por Cantineau (1940: 222) para la variedad sedentaria de Mostaganem, por lo que podemos suponer que es influencia de esta sobre el habla de los beduinos, aunque no todas las variedades de la zona A conservan las interdentales (Grand'Henry 1976: 11-12). Ejemplos: hädi "esta", tətqal "ella es pesada", nəḥhortu "aramos", tlāta "tres", tmānya "ocho", nwā dar "gafas", yḍdonn "él cree, piensa".

2.1.2.4. La enfatización de $r$ es un rasgo evidente. Ejemplos: $f$ əḍ-ḍar "en la casa", nəğğg $\bar{a} r$ "carpintero", fi raḩba "juntos", rāni mwālaf "estoy acostumbrado".

2.1.2.5. En el imperfectivo e imperativo de los verbos sanos de la forma I se produce geminación de la primera consonante cuando hay un sufijo de femenino, $-i$ ( $2^{\mathrm{a}}$ pers. sing.), o de plural, $-u\left(1^{\mathrm{a}}, 2^{\mathrm{a}}\right.$ y $3^{\mathrm{a}}$ plural). Este fenómeno se produce con la finalidad de conservar la posición de la vocal y mantener la estructura silábica cerrada (Marçais 1977: 29) ${ }^{(9)}$. Ejemplos: təggoSdi “tú permanecerás, estarás" (f.), taddoxli "tú entras" (f.), nəššorbu "nosotros/as bebemos", taggal€u “arrancáis", yəxxoržu "ellos salen”, addoxli “¡entra!” (f.), addoxlu "¡entrad!”.

2.1.2.5.1. Esto también ha sido localizado en tres sustantivos con el esquema singular femenino CvCCa cuando se le ha incorporado un sufijo que comienza por vocal. Cantineau (1940: 223) señala este fenómeno como influencia de las variedades beduinas en el árabe de Mostaganem. Ejemplos: sukkuntu (sukna) "su morada", xəddəmtu (xədma) "su trabajo", xəțtərtīn "dos veces" (xatra).

2.1.2.6. En cuanto a las asimilaciones, estas son las que aparecen:

\begin{tabular}{|c|c|c|}
\hline$\varsigma+h \rightarrow$ & $h h$ & $\begin{array}{l}\text { Ejemplos: ballahhha "¡ciérrala!", as-stīlo ntāḥha "su bolígrafo", al- } \\
\text { ğwāyoh ntāḥha "sus alrededores". }\end{array}$ \\
\hline$\zeta+\check{s}$ & $h \grave{s}$ & Ejemplos: lə-ȟšiyya "la tarde", lə-ȟša "la cena". \\
\hline$h+h$ & $\grave{h h}$ & Ejemplo: șāḥbaḥ $(<s ̧ \bar{a} h \underline{b} a h)$ "su amigo". \\
\hline$n+r$ & $r r$ & 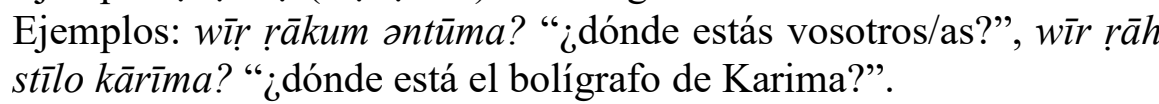 \\
\hline$l+t$ & $t t$ & Ejemplo: gātt li "ella me dijo". \\
\hline$t+d$ & $d d$ & Ejemplo: $d d \bar{\imath} r$ "ella hará". \\
\hline$t+\breve{g}$ & $d \breve{g}$ & Ejemplo: $d \breve{g} \bar{l} b$ "ella trae". \\
\hline$f+t$ & $t t$ & Ejemplo: šatti “tú has visto". \\
\hline$l+n$ & $n n$ & Ejemplo: xəwwnu nna "nos han robado". \\
\hline
\end{tabular}

(9) Este autor explica que este fenómeno tiene lugar en la región oranesa septentrional, Tremecén, en las variedades urbanas y rurales de Argelia, entre los nómadas del Tell de la región de la capital y de la de Constantina occidental, región de Collo y oasis de El-Kantara al sur de Constantina. Pero no así en las variedades beduinas del grupo A (Moscoso 2020b: 151). 


\subsection{Morfología verbal}

2.2.1. En cuanto a la conjugación, la terminación es - $t i$ para la $2^{\mathrm{a}}$ pers. sing. del perfectivo para el femenino y $-t$ para el $\mathrm{m}$. sing., siendo la $1^{\mathrm{a}}$, $-t$ para ambos géneros. En el imperfectivo y el imperativo hay diferencia en el género de la $2^{a}$ pers. del sing., marcándose el femenino con $-i$. Esta situación coincide para las variedades beduinas del Sáhara (Moscoso 2020b: 151). Marçais (1977: 36) explica que la marca de femenino solo aparece en dialectos conservadores como los de los beduinos. Ejemplos: roddīt "yo devolví, respondí" (m. y f.), ruht "tú fuiste" (m.), donnīti "tú piensas, crees" (f.), taggoYdi "tú te sientas" (f.), rgadti "tú has dormido" (f.), taxxadmi "tú trabajas" (f.), tadxal "tú entras" (m.), addoxli “jentra!” (f.).

2.2.2. En el imperativo cabe destacar la presencia de una vocal protética (Marçais 1977: 38), también presente en el árabe beduino del grupo A (Grand'Henry 1976: 43). Ejemplos: adxol

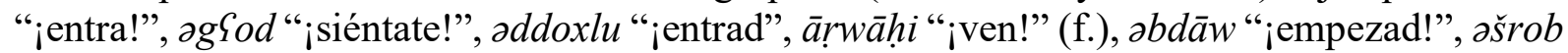
"¡bebe!”, shhadri "¡habla!”.

2.2.4. El sufijo del plural, tanto del perfectivo como del imperfectivo, de los verbos defectivos es $-u$, rasgo que coincide con el grupo beduino A del Sáhara argelino (Grand'Henry 1976: 49) y el beduino D (Cantineau 1940: 226), pero que no existía, sino $-\bar{l} w$ o $-\bar{a} w$, en el árabe de Mostaganem descrito por Cantineau (1940: 223). Ejemplos: Slāš y ğu Sandi? "¿por qué vienen a mi casa?", nqarrru "enseñamos", naqru "estudiamos", nə؟țu "nosotros damos", naddu "nos

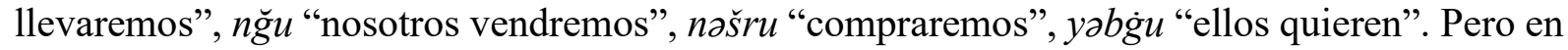
pocos casos, es $-\bar{a} w$ para los verbos defectivos cuyo imperfectivo acaba en - $a$ en el singular. Ejemplos: klāw "ellos han comido", Sțūha / Sṭâwha lah "ellos se la han dado", nabdāw "nosotros/as empezamos".

2.2.5. La forma VII es empleada habitualmente para expresar el significado reflexivo-pasivo. El grupo beduino B emplea esta y también $t$ - (Cantineau 1940: 226). Sin embargo, las variedades beduinas del Sáhara prefieren emplear la prefijación de $t$ - a la forma I (Moscoso

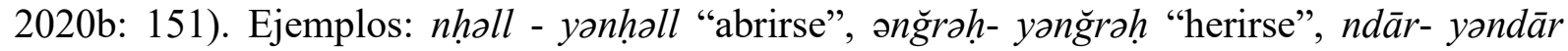
"hacerse", ngarḍtat man drāḥha "ella se fracturó su brazo", nəg்sal "lavarse", nəh̆rəg

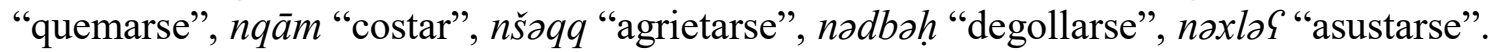

2.2.6. Presentamos a continuación algunos verbos, y algún participio y másdar, empleados que pueden servirnos de marcadores de isoglosas en el Magreb en particular y en el Mundo

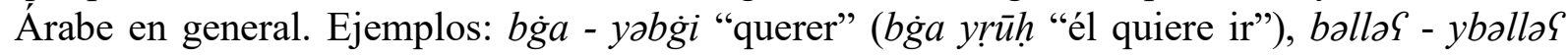

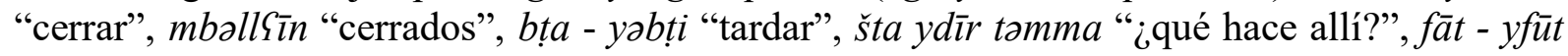
Sla "pasar por", fuwwet "pasar, hacer pasar", nkūn gā̧ad "estaré libre" (sentado), ğarrrad "registrar, prescribir", klāyəm "recoger, reunir", kahhh - ykohhh "toser", lāq - ylīq l "convenir a",

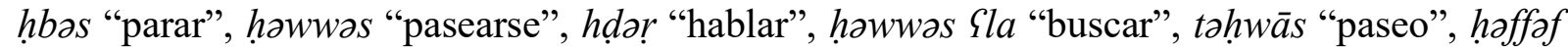
"arreglar la barba, pelar", stḩəqq "necesitar de (alguien)", nžəm - yənžəm "poder", tprōfiț f $\partial n-$

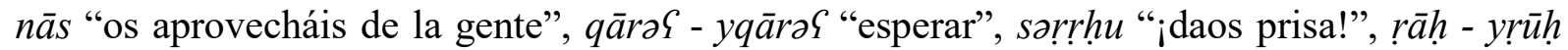
"ir", r frad "soportar, levantar", rəyyəh - yrəyyəh "descansar", ārwāh "¡ven!” (m.), ārāwhi “¡ven!” (f.), rgad "dormir”, saggam "arreglar, poner en orden”, stənna "esperar”, șāb - yṣīb "encontrar", tṣobb on-now "llueve", șoqșa - yșoqși "preguntar", țâq - yțīq "poder, ser capaz", tzəwwəğ "casarse", xāțīni "no es mi problema", xəbbəš "gradar (la tierra)", xuffi! "¡date prisa!" (f.), xəwwən - yxəwwən "robar", zād - yzìd "nacer", zəyyəd "dar a luz", zSəq Sla "mofarse de (alguien)”. 
2.2.7. El preverbio está ausente en el árabe de Mostaganem, al igual que en las variedades beduinas del Sáhara argelino (Moscoso 2020b: 152) y de otras partes del Mundo árabe, tanto en Occidente como en Oriente (Vicente 2008: 53). Ejemplos: āna ma nabgi š ot-țām bla lham "yo no quiero el cuscús sin carne", la, yākul gì̄ šwiyya l-xubz "no, solo come un poco de pan", qaysāš tadxol l ậd-d̄ạr? “¿Cuándo vuelve a casa?”.

2.2.8. Para el futuro, hay dos formas de expresarlo, o con el imperfectivo sin ir acompañado de ninguna partícula, tan solo el contexto indica que es este tiempo, o colocando la partícula $\dot{g} \bar{a} d i$, invariable, delante de este. La segunda de ellas tiene que ver con un futuro próximo, mientras que la primera es más lejano o poco exacto en el tiempo. Esta situación es la misma entre las variedades beduinas del Sáhara, en donde se emplea además el verbo $\dot{g} d a-y \partial \dot{g} d a$ "ir", seguido de imperfectivo (Moscoso 2020b: 151). Ejemplos: $\dot{g} \bar{a} d i$ trū $h i$ “tú irás" (f.), rāăğ $\dot{g} \bar{a} d i$ yği mal l-üzinn "mi marido vendrá de la fábrica", nathalla fìha "cuidaré de ella", nrodd lah al$\breve{g} w \bar{a} b$ al-yūm bāš yafroḥ"le responderemos hoy para que se alegre".

2.2.9. Y, por último, el participio activo $\boldsymbol{k} \bar{a} \boldsymbol{y} \boldsymbol{\partial}$ " "hay", es empleado en general de forma variable $\mathrm{y}$, en algún caso aislado, invariable. Ejemplos: kāyən os-sordīn "hay sardinas", kāyən os-slāta "hay ensalada", kāyən er-rīh "hay viento" (rīh es f.), kāyən stīlu "hay un bolígrafo", kāyna lxədma "hay trabajo", kāynīn əl-ḡāši "hay gente", tkūn kāyna blāṣa "habrá un lugar".

\subsection{Morfología nominal}

2.3.1. Comenzamos este apartado con el nombre.

2.3.1.1. La mayor parte de préstamos procede del francés y han entrado en Argelia durante la colonización de Francia, entre 1830 y 1962. Los que son de origen español han podido entrar a través de la lingua franca, hablada por marineros, estibadores y comerciantes en los puertos mediterráneos (Dakhlia 2008), por la presencia española en Orán y Mers El-Kébir entre 1509 y 1792 o por la llegada de moriscos y judíos que hablaban castellano o árabe andalusí -variedad en la que hay préstamos de lenguas romances de la Península Ibérica- a lo largo de los siglos XV, XVI y XVII. Y en cuanto a las voces procedente del turco, han debido de entrar durante la ocupación otomana que duró unos 300 años, hasta 1830.

2.3.1.1.1. De origen francés. Ejemplos: āsūrāns (fr. assurance) "seguridad social", blāyaz (fr. sing. bluse) "blusas", fisțta (fr. veste) "chaqueta", gāz (fr. gas) "gas", ìkūl (fr école) "escuela", $k \bar{a} d o$ (fr. cadeau) "regalo", kāmyūn (fr. camion) "camión”, kār (fr. car) "autobús", kāše (fr. cachet) "pastilla" (medicamento), p. kāšy yàt, klāsṣa (fr. classe) "clase, aula", kōnğge (fr. congé) "vacaciones", ksīdān (fr. accident) "accidente", kūzīna (fr. cuisine) "cocina", lämīri (fr. la mairie) "el ayuntamiento", lōkē (fr. loquet) "pestillo", līsi (fr. lycée) "liceo", mařše (fr. marché) "mercado", rānni mšūmer (fr. chomeur) "estoy en paro", rāni mdīgūṭi (fr. dégoûté) "estoy disgustado", rāāni mgāği (fr. engagé) "estoy enrolado en el ejército", rāni msūri (fr. assuré) "estoy seguro", mōtẹ re (fr. moteur) "motor", nōțīr (10) (fr. hotel) "hotel", ōto (fr. auto) "automóvil", plāka (fr. plaque) "placa", tprōfìtu $f$ on-nās (fr. profiter) "os aprovecháis de la gente", rākum rọțār (fr. retard) "llegáis tarde", sìma (fr. ciment) "cemento", sīgla (fr. seigle)

(10) Quizás pueda confundirse con el francés notaire, pero en el diálogo 33 del método está claro. La frase de donde ha sido extraído este préstamo es: la, batna f-en-nōtīr Sla xātọr ma nəYYarfu hatta hadd təmma "hemos pasado la noche en el hotel, ya que no conocemos a nadie allí”. Probablemente $f$ al-oțīl $>f$ al-loțill $>f$ al-loțīr por asimilación de $l$ a las $r$ de $x \bar{a} t ̦ a r$ y $n ə \Upsilon \zeta \partial r f u$ siguientes y luego paso de $l-l$ a $n-n$ por asimilación a la $n$ de batna. 
"centeno", srābīt (fr. serviettes) "toallas", šōfāg (fr. chaufage) "calentador", šôfēer (fr. chaufeur) "chofer", šüflēr (fr. chou-fleur) "coliflor", šūmāg (fr. chaumage) "paro, desempleo", trāketōr (fr. tracteur) "tractor", xəllīni trāankīl (fr. tranquille) "déjame tranquilo", ùzìn "fábrica", pl. ūzìnāt (fr. usine), al-ğurnān (fr. journal) "el periódico".

2.3.1.1.2. De origen español. Ejemplos: bāla (esp. pala) "pala", barṛāka (esp. barraca) "barraca", bəbbūš (esp. babosa, morisquismo) "caracoles", blāṣa (esp. plaza) "lugar, sitio", būšta (esp. posta, morisquismo) "correos", duro (esp. duro) "duro", fāmīlya (esp. familia) / Sāyla "familia", ìtru (esp. litro) "litro", dāyrīn al-kōla (esp. cola) "están haciendo la cola (de gente)", qūmēğğa (esp. camisa, morisquismo) "camisa" (pero qāmēğtək "tu camisa", sìmāna (esp. semana) "semana", sūma "precio", țōmāțīs (esp. tomates) "tomates", ť̌iña (esp. China) "una naranja".

2.3.1.1.3. Y de origen turco. Ejemplos: dīzān (tur. düzen) "herramientas", gurbi (tur. külube) "chabola", tazdām (tur. çantası) "monedero".

2.3.1.2. Presentamos a continuación algunas voces -también esquemas de plural- propias del árabe de Mostaganem, que pueden diferenciarla de otras variedades árabes del Magreb.

- Ejemplos de sustantivos y adjetivos: $b b a$ "mi padre", būya "mi padre", bəxnūq "pañuelo

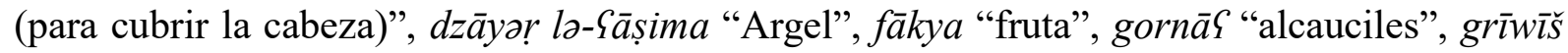
"dulcecitos hechos con huevo, harina, mantequilla y sal, fritos, enmelados y con sésamo", gaș $\ a$

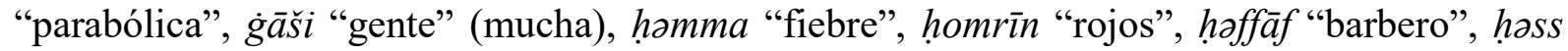
"ruido", karYīn "piernas" (krọiyya "mis piernas), kasra "pan redondo", kurrāas "cuaderno", kūša "panadería", mlīḥ "bueno, bien", mlīḥa "buena", marga "salsa", məšta "invierno", moțroḥ "colchón", məzəyya "ventaja, mérito, placer, gracia", maw īn "vajilla (acción de lavarla), mmūk / mmw ək "tu madre", no "lluvia", qūṭi țumāțīs "lata redonda de tomates", șahhha "gracias", sukkuntu šābba "su morada es bonita", šĭrāt "niñas pequeñas", təbyāẹ "acción de blanquear", tšina "una naranja", țāqa "ventana", pl. țwāqi, xāwti "mis hermanos" (xāwa), xətra "vez", xorțān "avena", xut mīlùd "la hermana de Miloud", xūya "mi hermano", xyāna "robo", zrōdiyya "zanahorias", al-ğazzār "el carnicero", ğ̄ì $\bar{a} z$ "ajuar".

- Ejemplos con sufijo -ān (sustantivos y adjetivos) : bardān "frío (que tiene)", fašlān "sin fuerzas", hummān "calor", ġuryān (< quryān / guryān) "bebé”, ž̄̌

- Ejemplos de participios con $\boldsymbol{m}$-: mkassra "rota", mraffah "que tiene recursos para vivir bien", mxəssar "estropeado".

- Ejemplos de plurales: al-byūt al-fwāga "las habitaciones de arriba", drāhəm "dinero", ktūba "libros", murḍa "enfermos", hwwānìt "tiendas", šlāġm "bigotes", xwātāt "hermanas", al-ğwārīn "los vecinos", xəbbāzīn / xəbbāza "panaderos", fallāḥīn / fallāḥa "agricultores".

2.3.1.3. El sufijo de dual -īn solo aparece en números, partes dobles del cuerpo y medidas. En el grupo beduino A puede aparecer en todas las categorías de palabras (Moscoso 2020b: 152).

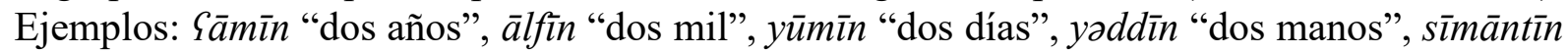
"dos semanas", sā̧tīn "dos horas", šzhrīn "dos meses".

2.3.1.4. En cuanto a los numerales, destacamos el uso de zūuz para dos. Ejemplos: $z \bar{u} \bar{g}{ }^{~} b n \bar{a} t$ "dos hijas". Cabe también destacar la aparición de $n$ entre los números 11 a 19 y lo numerado, corriente en la gran mayoría de variedades árabes argelinas (Marçais 1977: 178 y Moscoso 
2020b: 152), y las formas contraídas - sin - $a$ - cuando los números del 3 al 10 van seguido de la

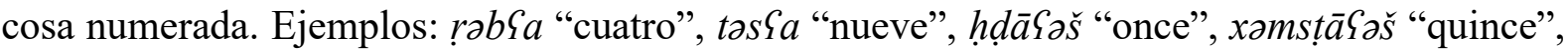

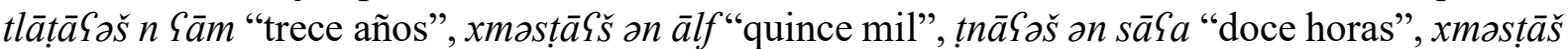

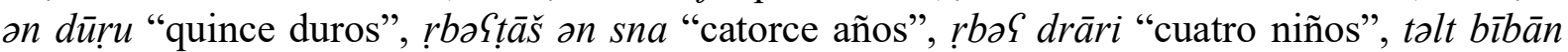
"tres puertas", talt byūt "tres habitaciones", təmn byūt "ocho habitaciones", Gəšrìn dūro "veinte duros", thīn u tlātīn "treinta y dos".

2.3.2. Entre los pronombres personales independientes, sobresale la distinción de género en $n t a(\mathrm{~m}$.$) - nti (f.) "tú" y la forma enfática ānāya "yo". Las formas plurales son invariables: ‘̣hna$ "nosotros/as", " ntūma "vosotros/as", hüma "ellos/as".

2.3.2.1. En el pronombre personal sufijado, destaca - $\boldsymbol{a h}$, después de consonante. Puede verse este en el grupo beduino D (Cantineau 1940: 226). Ejemplos: Yandah "él tiene", wāldah "su padre", winah al-h̆əmmām alli kuntu fìh? "¿dónde está el baño en el que habéis estado?”, gūl lah "dile", yəSți lah sukna "él le dará una vivienda", guddāmah "delante de él", yəŞərfah "él lo conoce", yrūh wāḥdah? "¿irá solo?", xəddəmtah "su trabajo". Pero - $h$ después de vocal. Ejemplos: wālìdīh "sus padres", ma da bīh "él desea" (no bah), șobtah "yo lo encontré", șoqșìh "pregúntale". También cabe destacar que $-k\left(2^{\mathrm{a}}\right.$ pers. sing.) es invariable, pero es $\mathrm{m}$. sufijada a $r \bar{a}$-, pero -ki si es f. Ejemplos: wīn rạ̄k sākən? "¿dónde estás viviendo?”, ma dāmək təkkəbri rāki taxxorfi "cuanto mayor eres, más tonterías dices", rāāki mrị̄a "tú estás enferma".

2.3.2.2. El pronombre reflexivo empleado es $\boldsymbol{r} \bar{u} \boldsymbol{h}$, , seguido de un pronombre personal sufijado; también en el grupo beduino A, aunque aquí puede aparecer, en menor medida, rāṣ y nəfs (Moscoso 2020b: 153). Ejemplos: ma yənğam yəxdəm rūḥu "él no puede trabajar por sí solo", rāh ğāyab rūhah f al-qrāya "él es aplicado en el estudio". Otra forma de expresar la reflexión es mediante el numeral wāhad. Ejemplos: tkūnu wāḩdkum "estáis solo vosotros", trūụh wāḥdək? “¿irás solo tú?”.

2.3.2.3. El demostrativo adjetivo de cercanía puede ser invariable, $h \bar{a} d$ $l$-, o tener una forma masculina sing., femenina sing. y plural, lo cual también coincide con el grupo beduino A (Moscoso 2020b: 154). Ejemplos: hād al-byūt / hādu l-byūt "estas habitaciones", hād al-bant / hādi l-bənt "esta chica", hādu l-iyyām "estos días", hādu z-zūğ ar-r̆ğāl "estos dos hombres".

El demostrativo adjetivo de lejanía posee las formas $d \bar{a} k$ al- / hādāk $ə l-(\mathrm{m}$. sing.), dīk al- / $h \bar{a} d \bar{\imath} k$ al- (f. sing.) y $d \bar{u} k$ al- / hādūk al- (pl.). Ejemplos: fi dāk al-woqt "en ese momento", $k i$

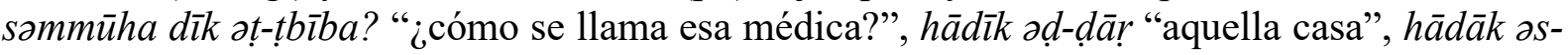
$\operatorname{smin}$ "aquel gordo".

Los demostrativos sustantivos de cercanía son $h \bar{a} d a$ (m. sing.), $h \bar{a} d i$ (f. sing.) y $h \bar{a} d u$ (pl.) y los de lejanía $h \bar{a} d \bar{a} k$ (m. sing.), hādìk (f. sing.) y hādūk (pl.).

2.3.3. Entre las preposiciones, sobresalen estas: $f i$ / $f$ "en", guddām "enfrente de, después de" (guddām la-fṭūr "después del desayuno"), ki / kìma "como", ḩdā- "junto a", murā- / mūr "detrás de" (mūrāya "detrás de mí, mūr bāāāh "detrás de su padre"), kìma mọāri "como de costumbre", füg "sobre".

2.3.4. Las conjunciones más relevantes son las siguientes: $b$ əṣ-ṣวḥh "pero", bìd la "mientras

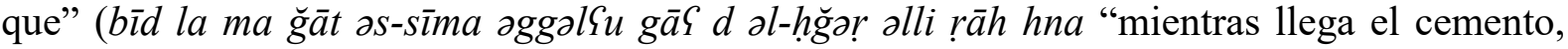
quitad todas las piedras que están aquí"), balli "que" (ygūlu balli ġādi yadxol l aṣ-ṣbițāạ "dicen

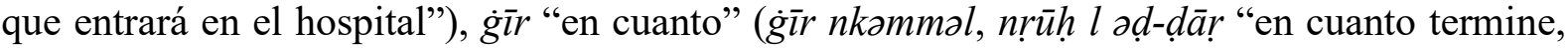
me iré a la casa"), həmmāla "entonces", ìla "si" (cond. real: woll ạh īla ruht al l-īkūl "por Dios que, si he ido a la escuela", īla ğ $\bar{a} t$ g̀ăli əšri noṣs ṛtal "si es caro para ti, compra media libra"), 


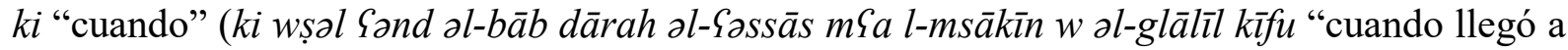
la puerta, el guardián lo puso junto a los pobres y los miserables como él"), kūn (cond. irreal,

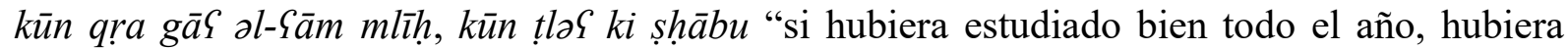
progresado como sus compañeros"), lūkān "si" (cond. irreal, lūkān dži mYāna loṣ-ṣbịțār xīr "si vinieras con nosotros al hospital, sería mejor", huwwa, lukān yaskun wāḥdah, xīr "él, si viviera solo, mejor"), ma dām "mientras" (ma dāmək təkkəbri rākki taxxorfi "cuanto mayor eres, más

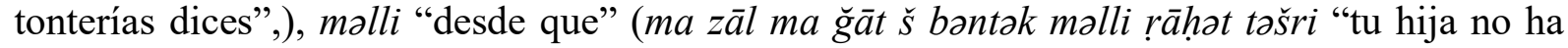
venido todavía desde que se fue a comprar"), mīn "cuando" (nti mīn tkammli xəddəmtək, ārwāh

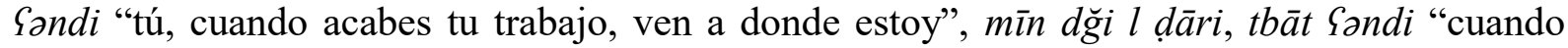
vengas a mi casa, pasarás la noche en ella"), Sla xāțr / Sla xāțor šs "porque, ya que" (râna rāạhlīn Sla xătar š hna Səndna ḍ-ḍ̄q bazzāf "nos vamos, ya que aquí estamos muy estrechos").

2.3.5. Entre los adverbios figuran: āktor "más", bārka / bārk "es suficiente", bəzzāf "mucho",

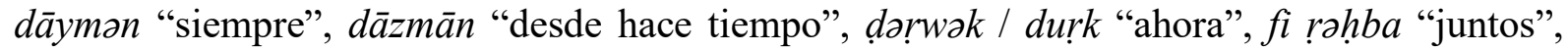
guddām "antes” (Clāš ma gultu lna š guddām? "¿por qué no nos lo habéis dicho antes?”), ġadwa / godwa "mañana", ġāya "estupendo, perfecto", $h \bar{a} k$ "así", $h \bar{a} k k a$ "así", $h \bar{a} w$ "claro que sí", shna / hna "aquí", kìma hāk / hākka "así, de esta forma", kïf kîf "igual", labda "siempre" (labda fi $z \bar{u} \bar{g}$ "siempre los dos"), ma gad "pasado mañana", ma zāl "todavía, todavía no" (ma zālat mrìda "todavía está enferma", ma zālu ma ğāw š "ellos todavía no han venido", shnna mā zālna mrāọ "nosotros todavía estamos enfermos", mā zāl al-hāl "todavía no es el momento", onta ma zəlt

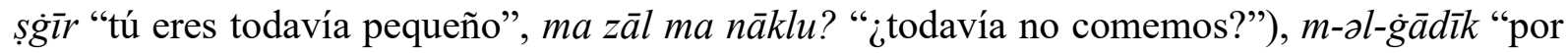
allí, mənna "aquí", mənna Sla "de aquí a" (mənna Sla rubৎ sā̧a "de aquí a un cuarto de hora"),

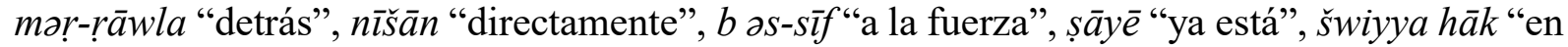
un ratito", tāni "también", təmma "allí", wāh "sí", wāqūla / bālak "quizás", b al-xoff "deprisa", yāməs "ayer", Sla yəmna "a la derecha", Sla l-yəsra "a la izquierda",

2.3.6. Los cuantificadores empleados son: $d$ / hāda šḥāl "cuánto" ( $d$ / hāda šḥāl ma ğa š

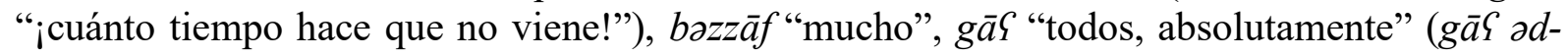
drāri "todos los niños", gā $\varsigma$ alli yaxxadmu "todos los que trabajan", banti gā $\varsigma$ ma rogdat $\check{s}$ "mi hija no durmió nada de nada", āna gā $\subseteq$ ma kmìt $\check{s}$ "yo no he fumado en absoluto"), kull šây "todo".

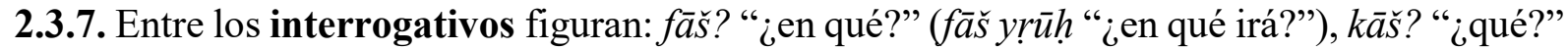
(kāšs ma șārr? “¿qué ha ocurrido?”, kāšs ma dərtu? "¿qué habéis hecho?”, w ənta təstənna kāšs hadd? “y tú, ¿esperas a alguien?”), ki? “¿cómo?” (ki sammūk? “¿cómo te llamas?”, lit.: “¿cómo te han llamado?”, ki rāk dāyr? “¿cómo estás?”), mən? "¿quién?” (bənt man? “¿de quién eres hija?”), mnāš “¿de qué?”, šta? “qué, cuál” (šta Səndu al-gallīl? “¿qué tiene el miserable?, šta

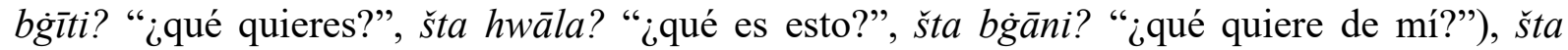
hwāla? "¿qué es eso?", šta hwāla hāda...? "¿qué es este... ?”, šta hwāla hādi..? "¿qué es esta?”, šta hwāla hādu...? "¿qué son estos?" (šta hyāla hādi alli kānat fi ğ̄̉bak "¿qué es eso que hay en tu bolsillo?", u hādi šta y(h)āla? "y esto, ¿qué es?”), wāš? “¿qué?, ¿cuál?” (wāš men n-nhārr rāna l-yūm? "¿qué día es hoy?”), wīn “¿dónde?” (wīn rạāk sākan? “¿dónde estás viviendo?”, wìnha l-blād alli kuntu fìha? "¿dónde está el país en el que estuvisteis?", ma Səndi wìn nbāt "no tengo donde pasar la noche”, winha al-blād alli kuntu fìha? “¿cuál (dónde) es la ciudad (país) en la que habéis estado?”), wīnta? “¿cuándo?” (wīnta tadxol l oṣ-ṣbịtār?? “¿cuándo entrará al

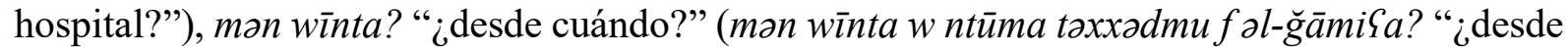
cuándo trabajáis en la universidad?”), woqtāš / qəysāš “¿cuándo?”, 乌ənd mən? “¿a casa de quién?” (Gand man ruhtu? “¿a casa de quién fuisteis?”). 
2.3.8. Entre las exclamaciones, hemos entresacado estas dos: həyya "¡venga!, ¡vamos!", Sla $b \bar{a} h !$ "¡es por eso!".

2.3.9. La partícula de relativo empleada, al igual que en el resto del Magreb es alli. Junto a esta,

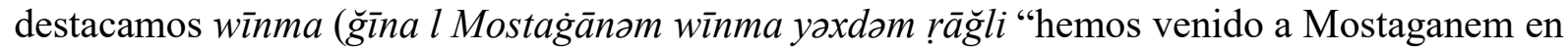
donde trabaja mi marido") "en donde" y bā̌s "con qué" (Gəandək bāš txəllloṣ "¿tienes con qué comprar?").

\subsection{Sintaxis}

2.4.1. La posesión en el árabe de Mostaganem se construye, en general, sufijando un pronombre al sustantivo. Esta forma sintética es la usual en el grupo beduino A (Moscoso 2020b: 160) Ejemplos: bābkum "vuestra puerta", bīti "mi habitación", blāṣtək "su sitio", dāru "su casa", ḍărkum "vuestra casa", fțūrok "tu desayuno", fi woqtu "en su tiempo", mərtu "su mujer", qrāyatha "su estudio", rāžzalha "su marido", šugilak "tu trabajo", țarbūšti "mi sombrero", ūlādhum "sus hijos", ülādi "mis hijos", wuğhah "su rostro", xālah "su tío materno".

2.4.1.1. $Y$ en algún caso mediante la partícula analítica $n t \bar{a} \varphi-$, invariable, frecuencia que coincide con el grupo A; en este suele ser vairable $m t \bar{a} \varphi$ - (m.). $m t \bar{a} \varsigma \partial t-$ (f.) y $m t \bar{a} w \varsigma$ - (Moscoso

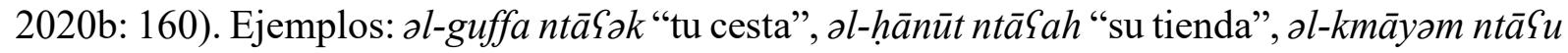

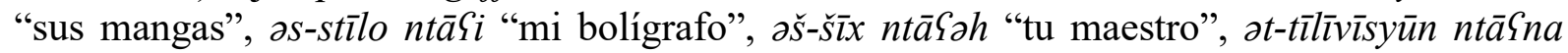

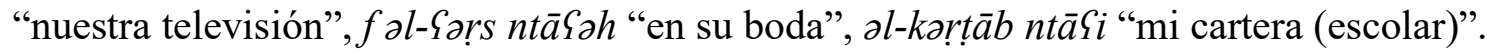

2.4.2. El genitivo más empleado es el sintético, coincidiendo también con las variedades beduinas del grupo A (Moscoso 2020b: 159). Ejemplos: bāb dārna "la puerta de nuestra casa", mər̆t Malīk "la mujer de Malík", xədmət bba "el trabajo de mi padre", xədmət mma "el trabajo de mi madre", bāb el-hawš "la puerta del patio", bìt ə̌̌s-šìñat "la habitación de las niñas", woqt la-fțūr "el momento del desayuno", rīht ad-duxxān "el olor del humo", xədmat aḍ-ḍâr "el trabajo de la casa".

2.4.2.1. Y le sigue en segundo lugar la construcción analítica, al igual que en el grupo A (Moscoso 2020b: 159), este último con la partícula variable $m t \bar{a} \varphi$ - como en la posesión.

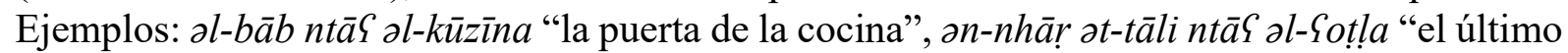

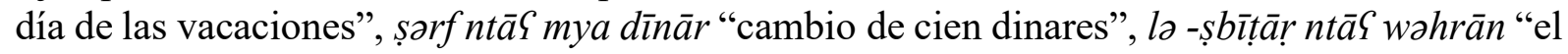
hospital de Orán", l-ūzinn ntā̧ s-sukkar "la fábrica de azúcar".

2.4.3. La partícula presentativa $\boldsymbol{r} \bar{a}$-, seguida de verbo o de un participio activo, se emplea para expresar la concomitancia y si va seguida de predicado no verbal, se usa para expresar una oración nominal (Boucherit 2002: 61-62, 69-70 y 78). Ejemplos: wìr rāạ r rāàh? "¿dónde estás

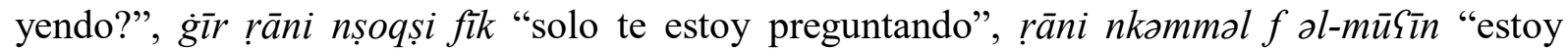
terminando de lavar los platos", rāni nasməS fik "te oigo", rāhum bāigiyyīn yball "quieren cerrar la tienda", rāni ğây "voy", rāh sākan fi gurbi "vive en una chabola", rāni rạayha

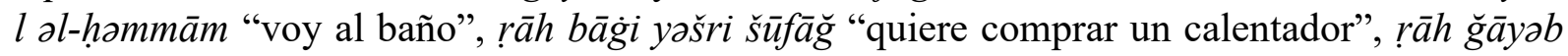
rūhah $f$ al-qrāya "él es aplicado en el estudio", rāni nḩəwwsu "estoy buscando", rāki gā $S d a$

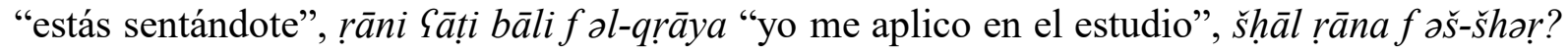

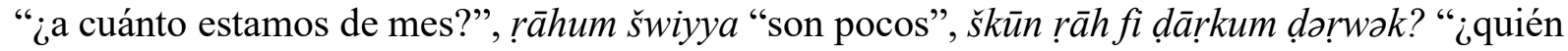
está en vuestra casa ahora”, šhāa rrāhi s-sā̧a? "¿qué hora es?", rāni bordān "tengo frío", alkūzinna rāhi məḥlūla "la cocina está abierta", rāk mrị̄ "estás enfermo", rāki mrị̣̂a "tú estás 
enferma", rāni mwālaf "estoy acostumbrado", ma ni š mahbūl "no estoy loco", al-mākla ma rāhi š liyya "la comida no es mía", ma rāăh š fìh "no está en él".

2.4.4. La negación de la oración nominal se realiza con māši. Ejemplos: mā̌ši l-yūm "no es

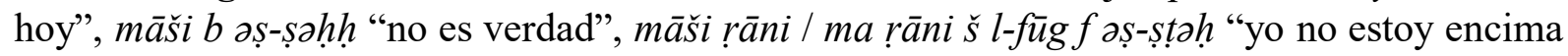
en la terraza", ma rāk š mrị̄ "no estás enfermo".

2.4.5. Por último, es interesante destacar que el giro $\boldsymbol{m a} \boldsymbol{d a} \boldsymbol{b} \overline{\mathbf{c}}$ - no es tan usual, solo hemos encontrado un ejemplo. Es una construcción que se emplea seguida de un pronombre personal sufijado y un imperfectivo o imperativo. Expresa deseo de hacer algo. Ejemplo: ma dā b-iyya nəšrob "me gustaría, desearía beber". En su lugar, el árabe de Mostaganem emplea el verbo

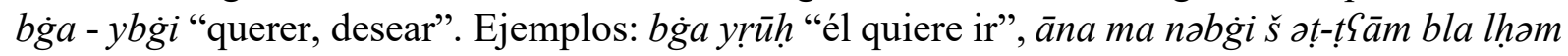
"yo no quiero el cuscús sin carne”, šta bg̀itti? “¿qué quieres?”. Esta situación no es la descrita entre las variedades beduinas del grupo A, en donde el giro ma $d a b \bar{l}$ - es bastante empleado (2020b: 160).

\subsection{Conclusiones}

El método inédito que hemos presentado se engloba dentro de un período posterior a la independencia de Argelia en el que se llevaron a cabo, por un lado, el método kama:l (1983) y, por otro, una serie de publicaciones en árabe argelino moderno que pretendían contribuir a la arabización del país: Tapiéro 1971, Fekhar y Deville 1966-1972 y Feddi y Deville 1973-1975; y también de árabe argelino: Tapiéro 1957 y Darmaun 1963. Fue escrito entre 1970 y 1978, basándose en principios estructuralistas, al igual que kama:l, y continúa empleándose para la enseñanza del árabe argelino en la diócesis de Orán. Su impulsor fue el P. Jean Paul Champenois y en su puesta a punto colaboraron el P. Michel Vidil y el P. Philippe Moysan.

La redacción del manual surge por la necesidad del P. Champenois de aprender árabe argelino a su llegada a Mostaganem y tras un año en Argel aprendiendo con el método kama:l. Hemos reproducido en este artículo el proceso de gestación del método y cómo, tras la guerra argelina de los años 1990, el P. Moysan inicia la edición del manual que el P. Champenois le dejó tras su regreso a Francia al inicio de esa década. El P. Moysan pudo pasar los textos al ordenador, escribiéndolos también en grafía árabe. Una parte del material quedó sin terminar y otra solo pudo ser escaneado desde el texto escrito a mano. Son 90 lecciones divididas en tres bloques de 30, cada uno equivale a un año de estudio. Los ejercicios son del tipo de los drills. Los audios se corresponden con los 90 diálogos y los ejercicios hasta la lección 55. Las pautas metodológicas son las propias de un método estructural: adquisición de estructuras de frases, memorización de las lecciones y progresión rigurosa apoyándose en la gramática.

El árabe de Mostaganem pertenece a la región oranesa delimitada por Cantineau (1940). Ya en este año, este dialectólogo dio a conocer el retroceso de la variedad sedentaria de esta ciudad como consecuencia de su beduinización. Los datos extraídos del método, escrito en los años 1970, treinta años más tarde, dan fe de ello y de la pérdida de los rasgos sedentarios expuestos por Cantineau. Las características más importantes que han sido presentadas en este artículo para el árabe de Mostaganem son: 
$\checkmark$ Alternan la realización de $g$ y $q$, aunque la primera es más empleada.

$\checkmark$ Realización $\breve{g}$.

$\checkmark$ Ausencia de interdentales.

$\checkmark$ Geminación de la primera consonante en el imperfectivo de los verbos sanos ante el sufijo - $i$ de femenino y $-u$ de plural, fenómeno que se extiende a los sustantivos con esquema $\mathrm{CvCCa}$ al añadírseles un sufijo pronominal vocálico.

$\checkmark$ Terminación - $t i$ para la $2^{\mathrm{a}}$ pers. sing. f. del perfectivo. En el imperfectivo y el imperativo también hay diferencia de género, siendo el sufijo de femenino $-i$.

$\checkmark$ Vocal protética en el imperativo.

$\checkmark$ Sufijo plural $-u$ para el imperfectivo de los verbos defectivos y $-u$ o $-\bar{a} w$ para el perfectivo.

$\checkmark$ La forma VII sirve para expresar la voz reflexivo-pasiva.

$\checkmark$ Ausencia de preverbio.

$\checkmark$ Abundan los préstamos del francés, seguido de los del español y el turco.

$\checkmark$ Presencia de $n$ entre los numerales del 11 al 19 cuando van seguidos de los numerado.

$\checkmark$ Pronombre persona sufijado - $a h$ para la $3^{\text {a }}$ pers. m. sing. seguido de consonante.

$\checkmark$ Empleo de la partícula analítica $n t \bar{a} S$ en el posesivo y el genitivo, aunque el uso de la construcción sintética parece mayor.

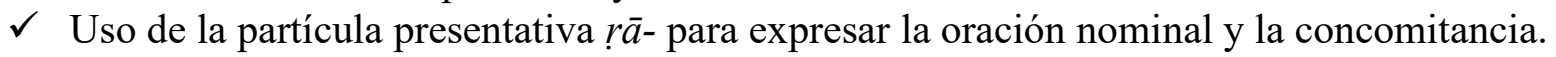




\section{BIBLIOGRAFÍA}

BOUCHERIT, Aziza (2002) : L'arabe parlé à Alger. Aspects sociolinguistiques et énonciatifs, Paris - Louvain : Peeters.

CANTINEAU, Jean (1937) : « Les parlers arabes du département d'Alger », Revue Africaine, $\mathrm{n}^{\circ}$ 7273, pp. 703-711.

CANTINEAU, Jean (1938-1939) : «Les parlers arabes du département de Constantine », Quatrième Congrès de la Fédération des Sociétés Savantes de l'Afrique du Nord, vol. I, Rabat, vol. II: Alger.

CANTINEAU, Jean (1940) : «Les parlers arabes du Département d'Oran », Revue Africaine, $\mathrm{n}^{\circ}$ 84, pp. 220-231.

CANTINEAU, Jean (1941) : «Les parlers arabes des territoires du Sud », Revue Africaine, $\mathrm{n}^{\circ}$ 85, pp. $72-77$.

Champenois, Jean Paul, Vidil, Michel \& Moysan, Philippe (1970-1978) : Méthode A.P.M. (arabe parlé à Mostaganem, Orán : Diocèse d'Oran.

DARMAUN, Henri (1963) : Recueil de textes algériens, Paris : Librairie C. Klincksieck.

DAKHLIA, Jocelyne (2008) : Lingua franca. Histoire d'une langue métisse en Méditerranée, Arles : Actes Sud.

GrandGuiLlaume, Gilbert (1983) : Arabisation et politique linguistique au Maghreb, Paris : Maisonneuve et Larose.

GRAND'HenRY, Jacques (1976) : Les parler arabes de la région du Mzâb (Sahara algérien), Studies in Semitic Languages and Linguistics, $\mathrm{n}^{\circ}$ 5, Leiden : E. J. Brill.

Grandguillaume, Gilbert (1983) : Arabisation et politique linguistique au Maghreb, Paris: Maisonneuve et Larose.

kama:l. Méthode S.G.A.V. Arabe parlé algérien (Alger). Dialogues et lexique, Alger : Centre d'études diocésain, 1984.

MARÇAIS, Williams (1908) : Le dialecte arabe des Ulād Brāhīm de Saïda. Paris: Honoré Champion.

MARÇAIS, Philippe (1977) : Esquisse grammaticale de l'arabe maghrébin, Paris: Librairie d'Amérique et d'Orient - Maisonneuve.

Moscoso GARcíA, Francisco (2017) : «Árabe argelino moderno. Textos de Mahmoud Fekhar y Gabriel Deville», Anaquel de Estudios Árabes, $\mathrm{n}^{\mathrm{o}}$ 28, pp. 147-168 [http://dx.doi.org/10.5209/ANQE.55187, consultado el 03 de mayo de 2021].

Moscoso GARCIA, Francisco (2020a) : Dictons et traditions. Littérature orale et Orientalisme catholique au Sahara algérien. Boletín de Literatura Oral, anejo $\mathrm{n}^{\mathrm{o}}$ 2, pp. 1-1116. [https://doi.org/10.17561/blo.anejo2, consultado el 19 de enero de 2021].

Moscoso GARcíA, Francisco (2020b) : «El árabe del Sahara argelino: tipo A de Cantineau. A partir de la obra Dictons et traditions del P. Yves Alliaume», Revista de Historiografia Lingüistica Argentina, $\mathrm{n}^{\mathrm{o}}$ 12, 2, pp. 141-168.

[http://www.rahl.ar/index.php/rahl/article/view/190, consultado el 07 de abril de 2021].

TAPIÉRO, Norbert (1957) : Manuel d'arabe algérien, Paris : Librairie C. Klincksieck.

TAPIÉRO, Norbert (1971) : Manuel d'arabe algérien moderne, Paris : Librairie C. Klincksieck.

ViCENTE, Ángeles (2008) : «Génesis y clasificación de los dialectos neoárabes». Manual de dialectología neoárabe ed. por Federico Corriente y Ángeles Vicente, Estudios Árabes e Islámicos. Estudios de Dialectología Árabe, no 1, Zaragoza: Instituto de Estudios Islámicos y del Oriente Próximo. 


\section{APÉNDICE}

26. Dars setta u દašrîn : nešrû fi raḥba

- nehâr-le-rebea mâ tehdem š ?

+ lâ. nkûn gâ عed. calâš ? štâ tebgîi ?

- عalâ hâtter bâgî nešî́ "šofâj"

+ tebgî njî̀ meâk u nešrû fi raḥba?

- wâh, enta tacref tešn̂ hîr menni!

+ șahha ! عandek bâš etholloṣ?

- candî elf u mitîn dînâr .

+ bâlek ma nșíbû š "šofâj"

fi mostaġânem?

- ilâ mâ ikûn š kâyen.

enrûhu l-wahrân es-sûg el-jây

+ șaḥha ! in šâ' allâh

ikûn عandnâ z-zhar !

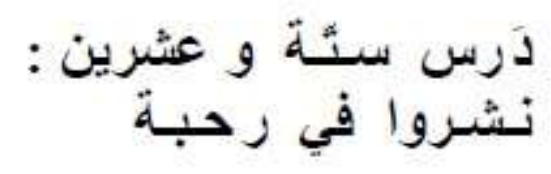

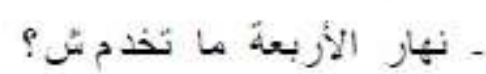

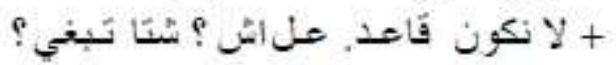

ـ على خاطر باغي نسري "تنو فاج"

+ثبغي نجي معلك و نسروا في ربك

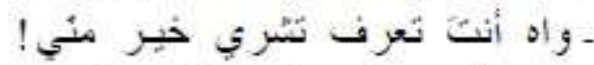

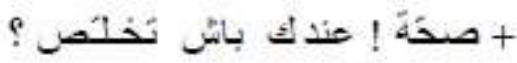

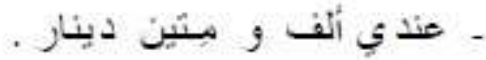

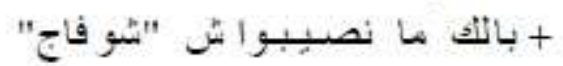

في مسئغنانمج

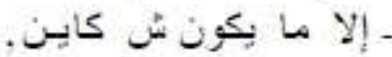

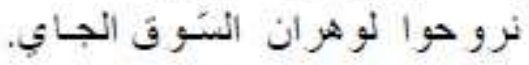

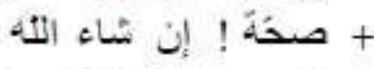

بكون عندان الزئهر

\section{Leçon 26: Nous achèterons ensemble}

- (te jour de) Mercredi, tu ne travailles pas?

+ Non, je serai libre [assis]. Pourquoi ? Qu'est-ce que tu veux?

- Parce que je vais [je suis voulant] acheter(un) chauffage.

+ Tu veux (que) je vienne avec toi et (que) nous achetions ensemble?

- Oui, toi, tu sais acheter mieux que moi.

+ D'accord! Tu as de quoi [ pour] payer?

- J'ai 1200 dinars.

+ Peut-être (que) nous ne trouverons pas (de) chauffage à Mostaganem?

- Sill n'y en a pas [il ne sera pas étant] nous irons à Oran la semaine prochaine.

+ D'accord! S'il plait à Dieu, nous aurons de la chance!

APM Dialogues 26 à 30 -Page 1 


\section{Leçon 30}

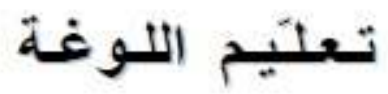

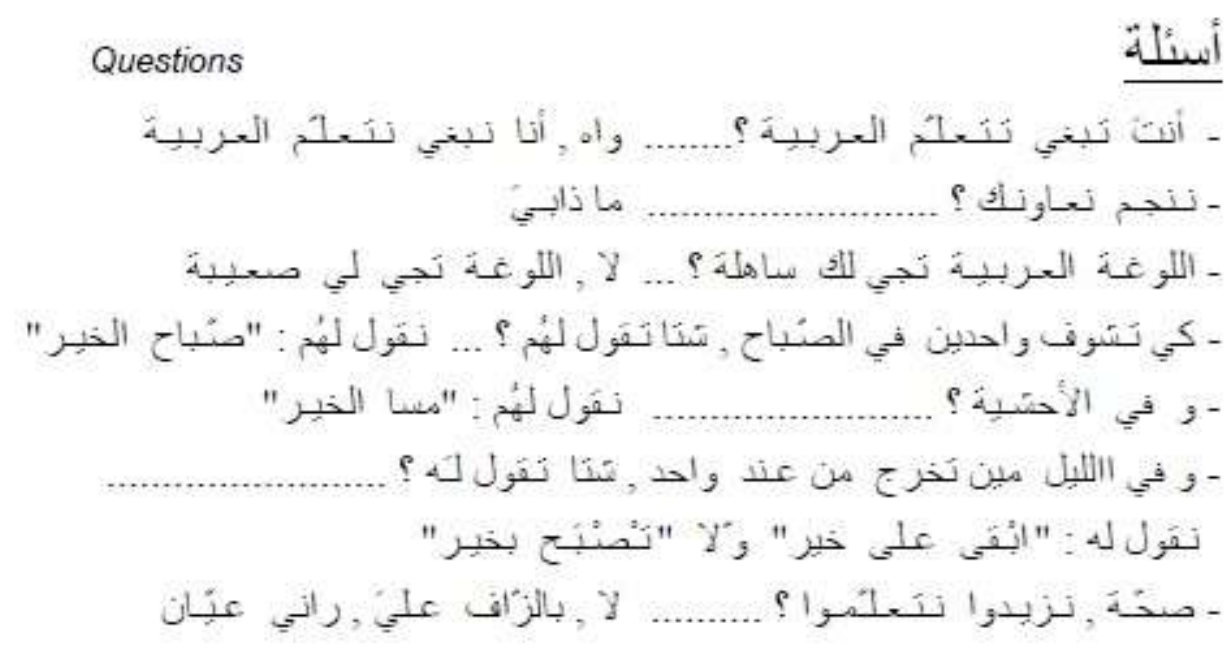

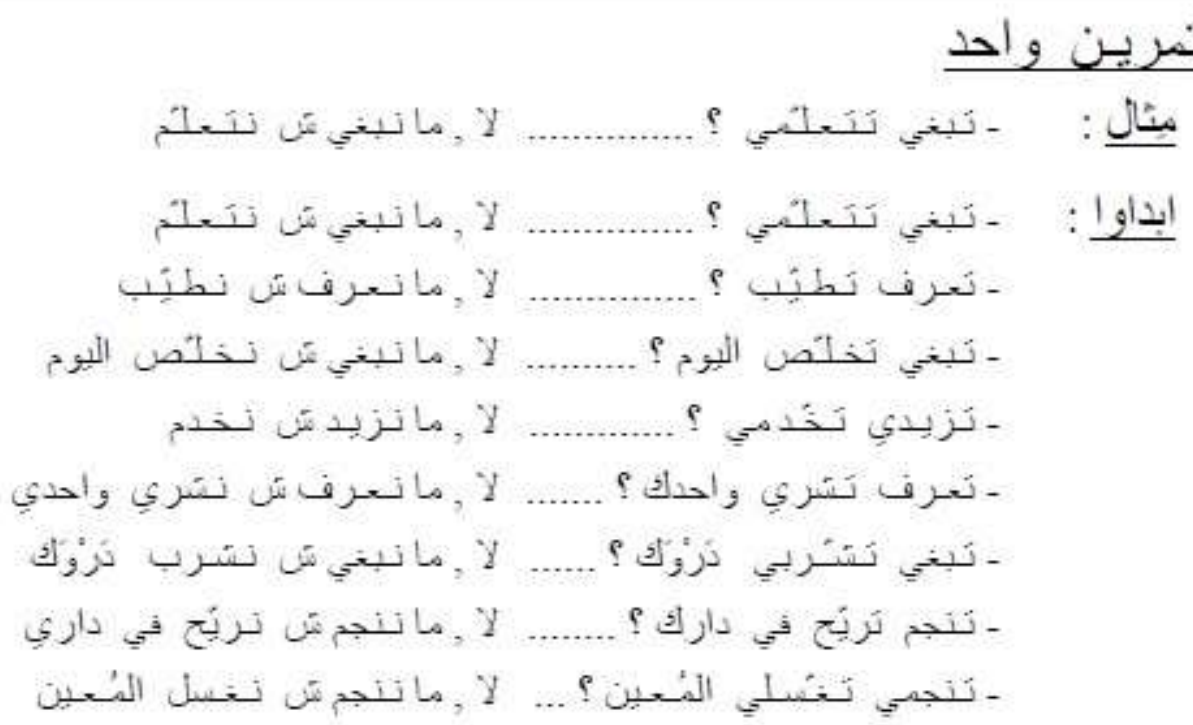

\section{Thème}

Je veux sortir pour me promener

Elle veut continuer à apprendre Parabe

Sais-tu conduire?

Les petits enfants ne savent pas bien parler

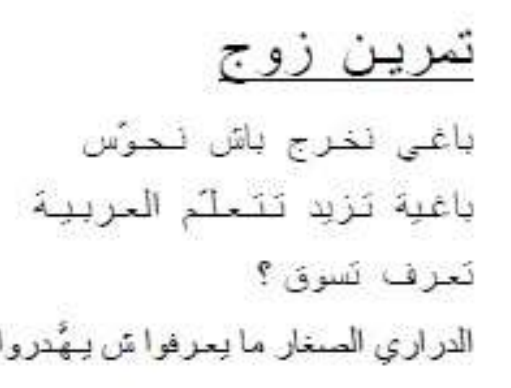

تمرين زوج

Méthode APM - Exercices des leçons 26 à 30 - Page $9 / 10$ 


\begin{tabular}{|c|c|}
\hline \multicolumn{2}{|c|}{ STRUCTURES - Leçons 31 à 35} \\
\hline \multicolumn{2}{|c|}{ Questions et Réponses } \\
\hline $\begin{array}{l}\text { - štâ šrît elnâ? } \\
\text { - wîn kunt el-jemea lî fâtet? } \\
\text {-škûn gâl-lek? } \\
\text {-šhâl geadtû men yûm? } \\
\text { - wînhâ l-blâd ellî kuntû fîha? } \\
\text { - candmen ruhtû? }\end{array}$ & $\begin{array}{l}=\text { šrît elkum el-hût } \\
=\text { kunt fî likûl } \\
=\text { eš-šî̉ huwa llî gâl-lî } \\
=\text { geadnâ eašrîn yûm } \\
=\text { kunna fî bârîz } \\
=\text { ruhnâ eand mohammed }\end{array}$ \\
\hline
\end{tabular}

\section{Propositions Relatives (elli)}

- kunt fel mârši u jibt lek elli iboșșek (j'ai été au marché et je t'ai apporté ce qu'il te manque)

- el-bodra Ili hawwest ealíha șobtha

(les légumes que jai cherchés, je les ai trouvés)

- eš-šî́b huwa lli gâl-lî

(le maître, c'est lui qui me l'a dit )

- wîn kuntû el-jemea lli fâtet?

(oủ étiez-vous vendredi dernier?)

- wînhâ H-blâd ellî kuntû fỉhâ ?

(Quelle est la ville dans laquelle vous étiez?)

- jînâ l-mostagânem winmâ yebdem râjlî ( Nous sommes venus à Mosta où travaille mon mari)

\section{Propositions Complétives (bellî)}

- mâ sandek mâ tgưli!

( Tu n'as rien à dire !)

- gâlû lî belli mâ jît š el-likûl!

(on m'a dit que tu n'as pas été à l'ècole !)

- kunt hâsba belli ma šî șeîba

(je pensais que ce n'était pas difficile)

- nḍonn belli hâd-el-merḍ șeíb?

(je pense que cette maladie est grave)

\section{Divers}

- anâ ma quut lek wâlu ! gîir râni noqșǐ fik ! (moi, je ne t'ai nien dit ! je t'interroge seulement)

- hawwestû gîir fî bârîz? (vous vous êtes promenés seulement à Paris?)

- ma nacerfû š hattâ hedd ( hatta wâhed) temma (nous ne connaissons personne là-bas)

- wîn kuntî guddâm lâ tîi l-mostağânem

- fi dâk el-woqt ma kunt ši metzawwej ?

- enfehhemmek calâš

- ulâdî râhum morḍa men yâmes (oủ étais-tu avant de venir à Mostaganem?)

( à ce moment tu n'étais pas marié ?)

( je te fais comprendre pourquoi)

(mes enfants sont malades depuis hier) 


\section{APM - Ecriture arabe}

$\underline{1} \underline{\text { ére }}$ Série Les voyelles et les lettres qui ne sont pas liées a la lettre suivante :

$$
\text { ي }
$$

La majorité des lettres arabes sont liées à la lettre précédente ainsi qu'à la lettre suivante. Chacune des lettres a une forme différente suivant qu'elle isolée ou bien insérée dans un mot: soit en début, en milieu ou à la fin. Ainsi, par exemple, le YA ( $=y$ ou $i)$ :

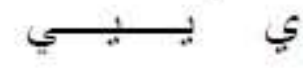

Sur les 28 lettres arabes il y en a six ( 2 voyelles et 4 consonnes) qui ne se lient pas à la lettre suivante :

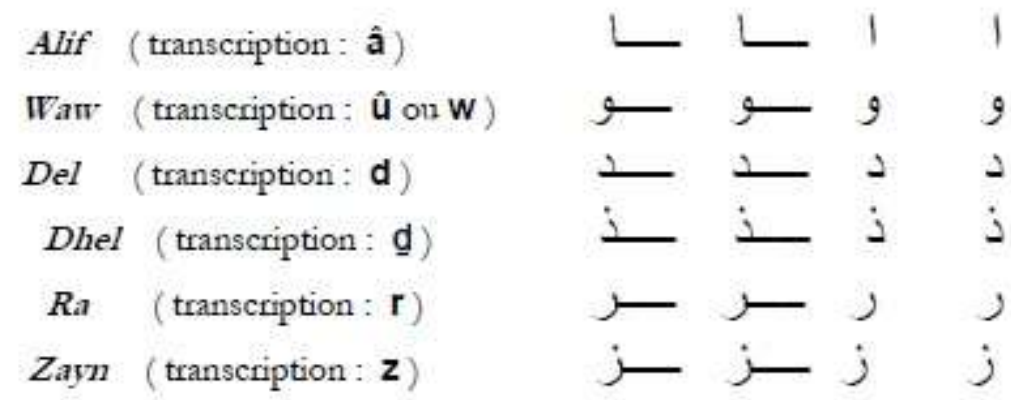

Attention à bien positionner les lettres par rapport à la ligne:

- l'écriture du Del et du $R a$ se ressemblent, mais le Del est plus fermé et reste au dessus de la ligne, tandis que le $R a$ descend au dessous (même chose pour le Dhelet le Zayn)

- Waw: boucle au dessus, queue en dessous de la ligne ... etc ...

\section{Exercice de lecture et d'écriture :}

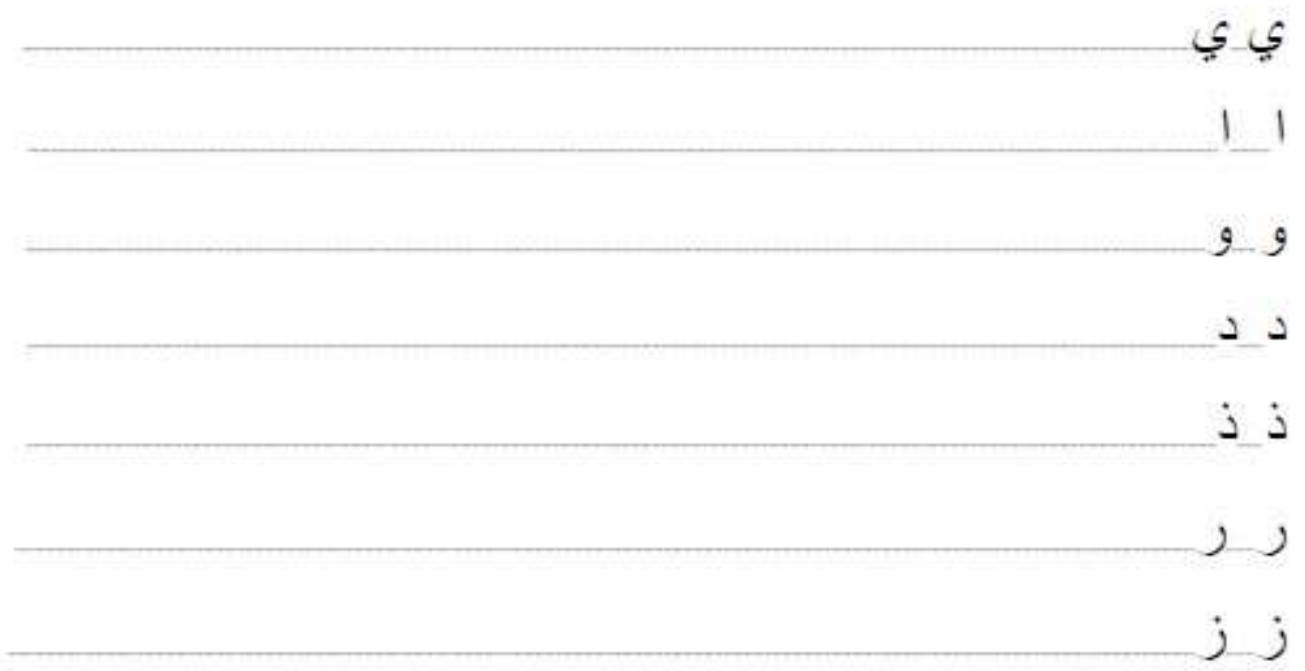

APM - Ecriture arabe - Page $2 / 13$ 
APM - Lexique FRANCAIS / ARABE - Leçons 1 à 30

\begin{tabular}{|c|c|c|c|c|c|}
\hline Mot français & \multicolumn{2}{|r|}{ Mot arabe } & Nature & genre & Leçon \\
\hline \multicolumn{6}{|l|}{ A } \\
\hline à & ntâع & ntâ c-na: à nous & prép. & & 3 \\
\hline a (elle) & Eandha & & v.avoir & $3 f$ & 5 \\
\hline a (ii) & candu (Alger) & sandah (Oran) & vavoir & $3 m$ & 4 \\
\hline à côté de & ḥdâ, aḥdâ & $a h d a ̂-k=$ à côté de toi & prép. & & 17 \\
\hline à Dieu ne plaise & bcîd eš-šerr & ( loin le mal) & expres. & & 18 \\
\hline à votre santé & b-șaḥhet kum & & expres. & & 28 \\
\hline abricots & mešmeš & & nom & coll. & $\begin{array}{c}10 \\
\text { vocab. }\end{array}$ \\
\hline acheter & šrâ & yešrî & verbe & & 26 \\
\hline affaires, choses & șâlha & $p l$ : șwâlah & nom & $m$ & 18 \\
\hline ai $\left(j^{\prime}\right)$ & Eandi & & v.avoir & 1 & 2 \\
\hline aider ( qqn) & Eâwen & icâwen & verbe & & 30 \\
\hline ail & tûm & & nom & coll. & $\begin{array}{c}10 \\
\text { vocab. }\end{array}$ \\
\hline vouloir & bg̉â & yebgî & verbe & & 10 \\
\hline ajouter, continuer & zâd & izid & verbe & & 10 \\
\hline allez! & heyya! & & interj. & & 13 \\
\hline alors, par conséquent & hemmâla & & $a d v$. & & 5 \\
\hline amen, qu'il en soit ainsi & amin & & nom & & 7 \\
\hline ami & șăheb & $p l$ : ș̣âb & nom & $m$ & 22 \\
\hline ancien vieux & qdîm & qdîma, qdâm & adj. & & 3 \\
\hline année & sna & $p l$ : snin & nom & $f$ & 5 \\
\hline on m'appelle & semmû-ni & inaccompli : isemmũ-ni & verbe & $3 p$ & 2 \\
\hline apporter & jâb & $\mathrm{ijib}$ & verbe & & 28 \\
\hline apprendre & teallem & itcallem & verbe & & 30 \\
\hline après & bead & & prép. & & 9 \\
\hline après-demain & mâ-ged & & nom & & 20 \\
\hline après-midi & aḥšiya & & nom & $f$ & 15 \\
\hline arabe & Earbiya & masc: carbî & adj. & $f$ & 30 \\
\hline argent & drâhem & & nom & pl & 12 \\
\hline arrivant & jây & jâya , jâyîn & p.prés. & & 27 \\
\hline artichauts & gornâع & & nom & coll. & 8 \\
\hline as (tu) & Eandek & & v.avoir & 2 & 2 \\
\hline assis, arrêté, inactif, oisif & gâced & gâteda, gâtedin & p.prés. & $m$ & 26 \\
\hline attendre & qârec & Alger: astenna & verbe & & 18 \\
\hline au dessus de & fûg & & $a d v$. & & 13 \\
\hline au nom de Dieu & bismillâh & & expres. & & 18 \\
\hline au revoir & b-es-slâma & slâma salut étemel. & expres. & & 7 \\
\hline au revoir & bqâ ealâ bîr & bqay, bqaw calâ hîr & expres. & $\mathrm{ms}$ & 7 \\
\hline aubergines & danjel & & nom & coll. & $\begin{array}{c}10 \\
\text { vocab. }\end{array}$ \\
\hline aussi également & tâni & & adv. & & 3 \\
\hline
\end{tabular}

Page $2 / 14$ 


\begin{tabular}{|c|c|c|c|c|c|c|}
\hline \multicolumn{7}{|c|}{ ALPHABET ARABE et transcription utilisée dans le cours d'arabe APM } \\
\hline Lettre & $\begin{array}{l}\text { Trans- } \\
\text { cription }\end{array}$ & finale & médiale & initiale & isolée & Prononciation \\
\hline$\underline{\text { alif }}$ & â & $\checkmark$ L & \llcorner & 1 & 1 & a long \\
\hline$\underline{\mathrm{ba}}$ & b & ـاب & + & $\rightarrow$ & ب & $\mathrm{b}$ \\
\hline$\underline{\text { ta }}$ & $\mathrm{t}$ & $ت$ & i & - & $\dot{\Xi}$ & $\mathrm{t}$ \\
\hline tha & $\underline{\mathrm{t}}$ & + & $i$ & $\dot{+}$ & $\dot{s}$ & th anglais de "the" \\
\hline djim & j & ج- & $\rightarrow$ & $\rightarrow$ & ج & dj \\
\hline ḥa & h & $\tau$ & $\sim$ & $\rightarrow$ & $\tau$ & $\mathrm{h}+$ contraction du gosier \\
\hline kha & $\mathrm{b}$ & خ் & $\dot{\sim}$ & $\dot{i}$ & $\dot{\tau}$ & jota espagnole, ch allemand \\
\hline del & $\mathrm{d}$ & $\perp$ & $\perp$ & $د$ & د & d \\
\hline dhel & $\underline{\mathrm{d}}$ & $\dot{-}$ & $\dot{-}$ & j & $\dot{j}$ & th anglais de "this" \\
\hline$\underline{\text { ra }}$ & $r$ & 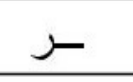 & - - ع & $\jmath$ & $\jmath$ & $\mathrm{r}$ roulé \\
\hline zine & $z$ & $j$ & $j$ & j & j & $z$ \\
\hline$\underline{\text { sine }}$ & s & س & س سـ & 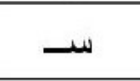 & س & s \\
\hline$\underline{\text { shine }}$ & š & شش & شــ & 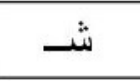 & ش & ch \\
\hline çad & Ș & صص & n & صـ & ص & s emphatique \\
\hline$\underline{\text { dad }}$ & d & ـض & ـــ & ض & 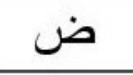 & d emphatique \\
\hline$\underline{\mathrm{Ta}}$ & t & $b$ & ط & ط & b & t emphatique \\
\hline dha & $z$ & ظـ & طـ & ظ & ظ & dhel ( $\underline{\mathrm{d}}$ ) emphatique \\
\hline aïne & $\varepsilon$ & $\varepsilon$ & $\rightarrow$ & ع & $\varepsilon$ & contraction du pharynx \\
\hline ghaïne & $\dot{\mathrm{g}}$ & 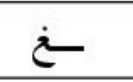 & $\dot{~}$ & غ & $\dot{\varepsilon}$ & r grasseyé (parisien) \\
\hline$\underline{f a}$ & $f$ & فـ & $i$ & ف & ف & $f$ \\
\hline qaf & $q$ & ــ & a & ق & ق & q guttura/ ou g de "gateau" \\
\hline$\underline{k e f}$ & $\mathrm{k}$ & كـ & $\leq$ & 5 & 5 & k \\
\hline lem & 1 & U & $\perp$ & \lrcorner & J & 1 \\
\hline$\underline{\operatorname{mim}}$ & $\mathrm{m}$ & + & - & 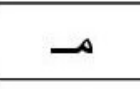 & r & $\mathrm{m}$ \\
\hline noun & $\mathrm{n}$ & - & $i$ & - & ن & $\mathrm{n}$ \\
\hline$\underline{\text { ha }}$ & $\mathrm{h}$ & 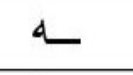 & $t$ & $\rightarrow$ & ○ & h expiré venant de la poitrine \\
\hline ta marbuta & a final & $\ddot{L}$ & & & $\ddot{0}$ & a bref ou et- avecliaison \\
\hline waw & w, û & g- & $g$ & 9 & 9 & ou ou w comme "ouate" \\
\hline ya & $y, \hat{\imath}$ & - & + & $\rightarrow$ & ي & i long ou y de "yatagan" \\
\hline
\end{tabular}

